\title{
Second Stage of Upper Bainite in a 0.3 Mass Pct C Steel
}

\author{
JIAQING YIN, MATS HILLERT, and ANNIKA BORGENSTAM
}

Upper bainite forms in at least two stages, the formation of parallel plates of ferrite and the transformation of the interspaces to a mixture of cementite and ferrite. The first stage was examined in a preceding metallographic study of the formation of ferrite in hypoeutectoid steels and the second stage, which is initiated by the occurrence of cementite in the interspaces, is the subject of the present study. The alloy from the preceding study will also be used here. The band of austenite in the interspaces between parallel plates is generally transformed by a degenerate eutectoid transformation when this band is thin. When it is thicker, it will transform by a more cooperative growth mechanism and result in a eutectoid colony, often with cementite platelets. A series of sketches are presented which illustrate in detail how the second stage of upper bainite progresses according to the present observations. The cooperative manner did not increase as the temperature was lowered because the tendency to form plates of ferrite was still increasing at lower temperatures, making the interspaces too narrow for the cooperative reaction to dominate over the formation of fine plates of ferrite.

DOI: $10.1007 / \mathrm{s} 11661-016-3902-\mathrm{z}$

(C) The Author(s) 2016. This article is published with open access at Springerlink.com

\section{INTRODUCTION}

FERRITE particles of various shapes appear early at the grain boundaries in isothermal transformation of hypoeutectoid austenite at fairly high temperatures. They were examined in a preceding study. ${ }^{[1]}$ Large groups of parallel plates will soon predominate, especially below the eutectoid temperature where pearlite can form and soon will predominate. Groups of ferrite plates will continue to form but to a smaller fraction. Below the "nose" temperature of pearlite they will soon predominate again until interrupted by martensite. It was thus possible to study the effect of temperature on the groups of ferrite plates over the whole range of temperature and it was observed that there is no sharp change of morphology that could indicate a transition of growth mechanism from Widmanstätten ferrite to the acicular ferrite of upper bainite. This supports the suggestion that the only difference between Widmanstätten ferrite and upper bainite is the presence of cementite in the latter.

Initiated by the occurrence of cementite at some time, depending on temperature, the austenite remaining in the interspaces between the ferrite plates will finally transform and the end product is defined as upper bainite. In the present study, the progress of the transformation initiated by cementite was studied with SEM, Scanning Electron Microscopy. The same alloy was employed as in the preceding study but two related

JIAQING YIN, MATS HILLERT, and ANNIKA BORGENSTAM are with the Department of Materials Science and Engineering, KTH (Royal Institute of Technology), Brinellvägen 23, 10044 Stockholm, Sweden. Contact e-mail: jiaqing@kth.se

Manuscript submitted June 23, 2016.

Article published online January 5, 2017 alloys were added. The microstructures of bainite have recently been discussed in two review papers ${ }^{[2,3]}$ but the present study was undertaken to examine what is generally regarded as the second stage of bainite formation.

In the preceding study it was essential to examine ferrite plates over their full length which is why that study emphasized grain boundary nucleated plates where one can identify the starting point. Parallel plates of ferrite often occur in large groups, which represent the first stage of bainite formation. Meh ${ }^{[4]}$ called this final microstructure feathery bainite.

In the present alloys feathers were found in the whole temperature range that was examined. Figures 1 and 2 give two examples (see Reference 1 for experimental procedure). Figure 2 from a low temperature gives an indication of how common the feathery microstructure can be. The term feathery describes the appearance in the plane of polish when there are parallel groups of plates on both sides of the grain boundary but Mehl also applied the term to a case where the parallel plates were present only on one side of the grain boundary. Such units could be as useful in the present study. An example is shown in the left-hand part of Figure 2.

For bainite there are two conflicting hypotheses which cannot be reconciled, the diffusional ${ }^{[5-8]}$ and diffusionless, ${ }^{[5,8,9]}$ which concern the behavior of interstitially dissolved carbon during the formation of acicular ferrite. This conflict is of minor importance for the present study, which focuses on the second stage initiated by cementite. It naturally involves diffusion of carbon. The interpretation of the microscopic progress of all stages of formation of upper bainite will here be based on the diffusional hypothesis. In the final section it will be discussed whether the diffusionless hypothesis 


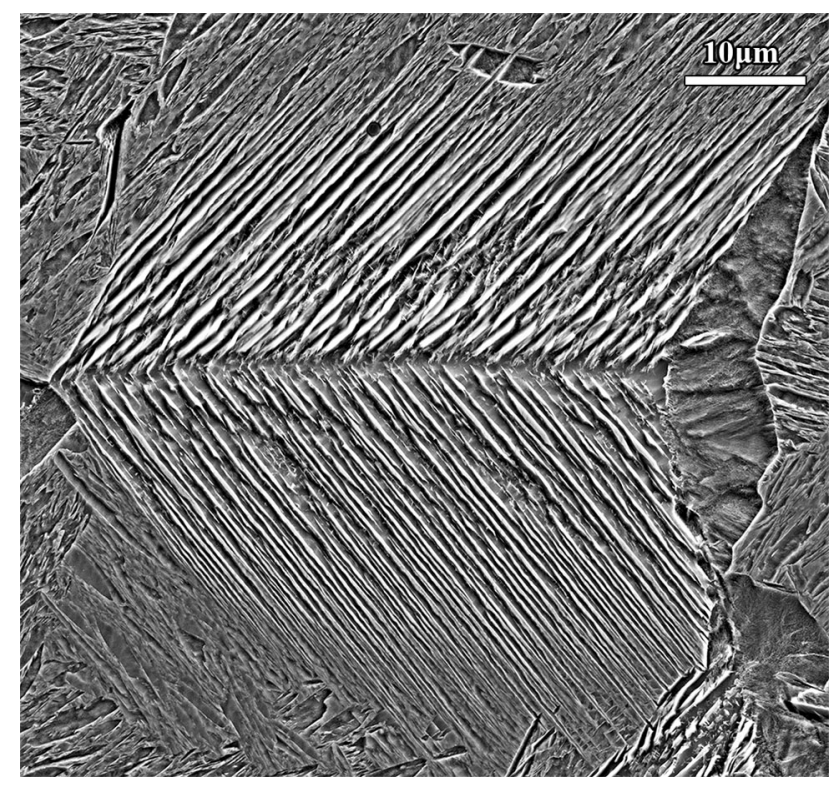

Fig. 1-Feathery bainite in SEM of FeSiC alloy after $1 \mathrm{~s}$ at $723 \mathrm{~K}$ $\left(450{ }^{\circ} \mathrm{C}\right)$.

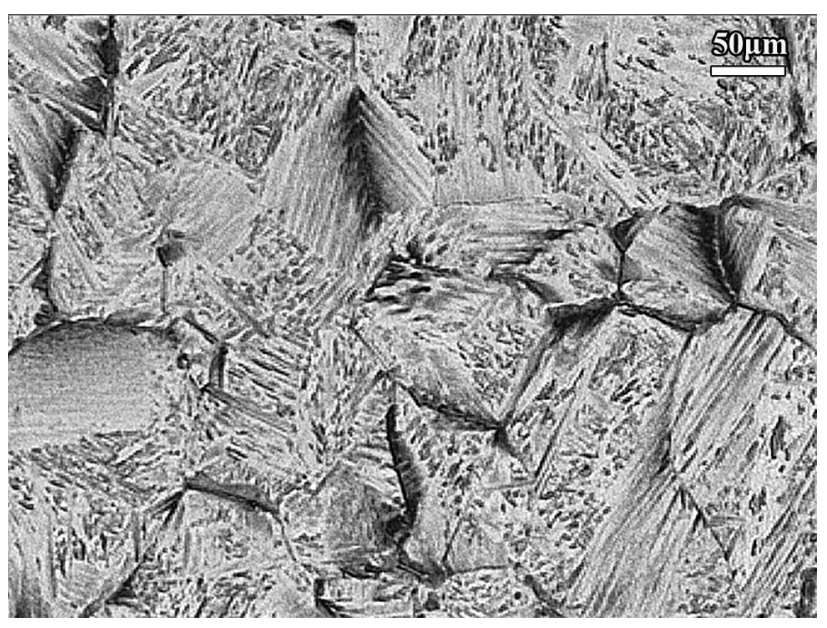

Fig. 2-Feathery bainite in LOM of FeSiC alloy after $5 \mathrm{~s}$ at $573 \mathrm{~K}$ $\left(300{ }^{\circ} \mathrm{C}\right)$.

can be reconciled with various observations. Another conflict $^{[8]}$ regards the behavior of the lattice atoms at the moving phase interface and will not be discussed.

\section{EXPERIMENTAL PROCEDURE}

The chemical compositions of the alloys and martensitic start temperatures are given in Table I. ${ }^{[10,11]}$ The study was mainly performed on the same FeSiC alloy with 0.5 mass pet $\mathrm{Si}$ as in the preceding study. 0.5 mass pet $\mathrm{Si}$ was used in order to delay the formation of cementite somewhat. Samples with a thickness of $2 \mathrm{~mm}$ and a size of $15 \times 8 \mathrm{~mm}$ were austenitized at $1473 \mathrm{~K}$ $\left(1200{ }^{\circ} \mathrm{C}\right)$ for 2 hours in protective argon atmosphere in order to achieve a reasonably large grain size to be able to study the growth over a convenient distance and also to decrease the interference by pearlite. The specimens were quenched into a Bi-Sn melt of selected temperatures with $50 \mathrm{~K}$ intervals. They were held in the melt for various times starting from 1 second and finally quenched in iced brine. All the samples were mechanically polished, ending with $0.05 \mu \mathrm{m}$ alumina suspension. Various etchants were used to reveal the microstructure among which 2 mass pet picral was used for light optical microscopy (LOM) while either 2 mass pct nital, Vilella's reagent (picric acid $1 \mathrm{~g}+$ hydrochloric acid $5 \mathrm{~mL}+$ ethanol $100 \mathrm{~mL}$ ) or a carbide etchant ${ }^{[12]}$ (picric acid $2 \mathrm{~g}+$ sodium hydroxide $25 \mathrm{~g}+$ distilled water $100 \mathrm{~mL}$ ) was applied for SEM. The SEM work was carried out with a field emission gun-scanning electron microscope (FEG-SEM) JEOL JSM-7800F (Japan Electron Optics Laboratory Ltd., Tokyo, Japan), operating at $15 \mathrm{kV}$ with a working distance of $7 \mathrm{~mm}$. The same electron microscope was used for EBSD (electron backscatter diffraction) study, an accelerating voltage of $15 \mathrm{kV}$ and a step size of $50 \mathrm{~nm}$ were applied. The EBSD data were processed with QUANTAX CrystAlign software.

\section{MICROSCOPIC OBSERVATIONS}

\section{A. Thickening of Ferrite}

The primary formation of ferrite plates was examined in the preceding study but the subsequent transformation of the interspaces between the plates depends much on their width, which is affected by thickening of the plates. It is thus convenient to regard three stages of the formation of upper bainite, (1) the primary formation of ferrite plates, (2) their thickening, and (3) the transformation of the remaining austenite bands in the interspaces, initiated by cementite. Thickening was included in the preceding study but some aspects will be considered here.

As illustrated in Figure 3, the plates usually thicken symmetrically and first it may be assumed that the carbon content will be concentrated in the remaining bands of austenite in the shrinking interspaces. Martensite is observed in the original austenite but thin bands of austenite, white, are observed between the plates, probably stabilized by high carbon contents. One could estimate the final thickness of the austenite bands if cementite would never form, e.g., by assuming full chemical equilibrium between ferrite and austenite. The carbon content of the present steels would then give a ratio of the austenite to ferrite thicknesses of $1 / 8$ at $823 \mathrm{~K}\left(550{ }^{\circ} \mathrm{C}\right)$ and even lower ratios at lower temperatures due to the increased equilibrium content of carbon in austenite. Thin bands of austenite will be called slabs in the following.

Close examination of Figure 3 reveals that neighboring plates sometimes touch each other and it is an interesting question where the carbon has gone. Figure 4 from the same specimen illustrates that a thick plate of ferrite actually consists of six thin plates that have merged when they made contact by thickening. They are now separated by ghost lines. Austenite in one of the 
Table I. Chemical Composition (Mass Pct) of Alloys, Martensite Start Temperature is Given from Calculation and Microscopic Observation

\begin{tabular}{|c|c|c|c|c|c|c|c|}
\hline Alloy & $\mathrm{Fe}$ & $\mathrm{C}$ & $\mathrm{Si}$ & $\mathrm{Mn}$ & $M_{\mathrm{S}}$, Andrew ${ }^{[10]}\left[\mathrm{K}\left({ }^{\circ} \mathrm{C}\right)\right]$ & $M_{\mathrm{S}}$, Stormvinter ${ }^{[11]}\left[\mathrm{K}\left({ }^{\circ} \mathrm{C}\right)\right]$ & $M_{\mathrm{S}}$, Microstructure $\left[\mathrm{K}\left({ }^{\circ} \mathrm{C}\right)\right]$ \\
\hline $\mathrm{FeSiC}$ & 99.1 & 0.28 & 0.52 & 0.06 & $675(402)$ & $699(426)$ & 623 to 673 (350 to 400$)$ \\
\hline FeMnC & 99.2 & 0.27 & 0.03 & 0.45 & & & 623 to 673 (350 to 400$)$ \\
\hline $\mathrm{FeMnSiC}$ & 98.7 & 0.26 & 0.51 & 0.48 & $671(398)$ & $683(410)$ & 623 to $673(350$ to 400$)$ \\
\hline
\end{tabular}

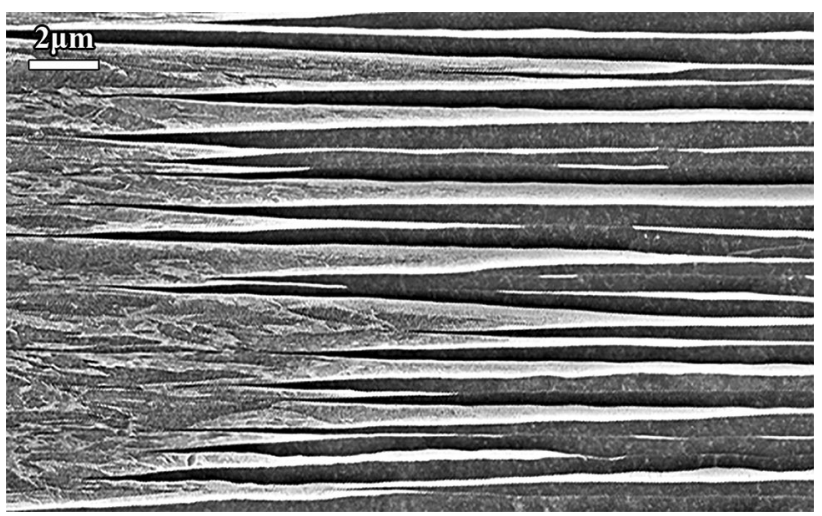

Fig. 3-SEM of plates of ferrite in feathery bainite in FeSiC alloy after $1 \mathrm{~s}$ at $823 \mathrm{~K}\left(550^{\circ} \mathrm{C}\right)$. Ferrite plates are black and the matrix is mainly martensite. When white, it may be austenite, retained due to high carbon content.

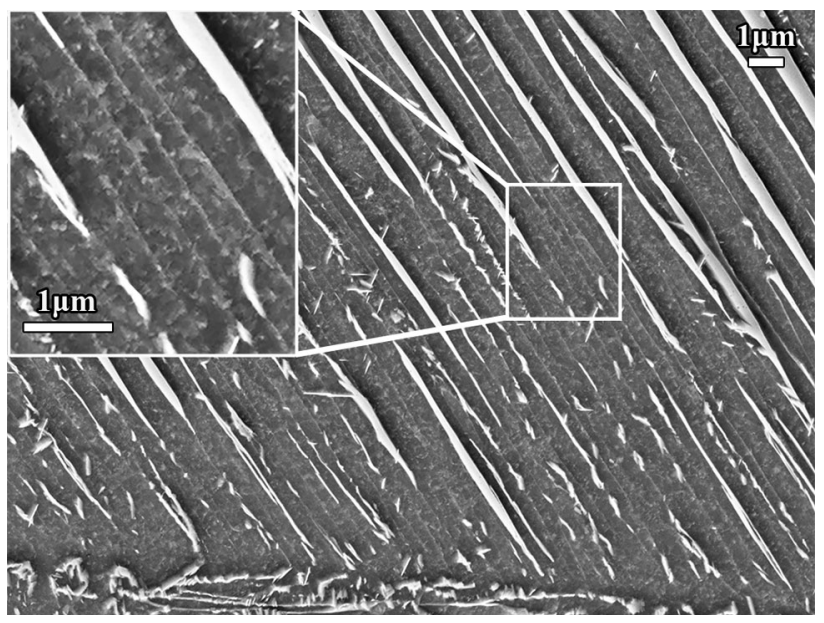

Fig. 4-SEM of feathery bainite in FeSiC alloy after $1 \mathrm{~s}$ at $823 \mathrm{~K}$ $\left(550{ }^{\circ} \mathrm{C}\right)$. White bands and lines are retained austenite, small white particles are cementite, dark background is ferrite. Insert shows ghost lines between merged plates of ferrite.

interspaces remains as a very thin slab that originates from the lower right corner of the micrograph. That indicates that the five ghost lines actually represent vanished interspaces. Such merger has been reported previously and was described as coalescence, e.g., by Ohtani et al. ${ }^{[13]}$ From the diffusional point of view one should wonder what happened to all the carbon that was originally dissolved in the band of austenite between the plates of ferrite, which were then much thinner. It must have escaped by diffusion, possibly through one or a few ferrite plates to remaining austenite on the other side or
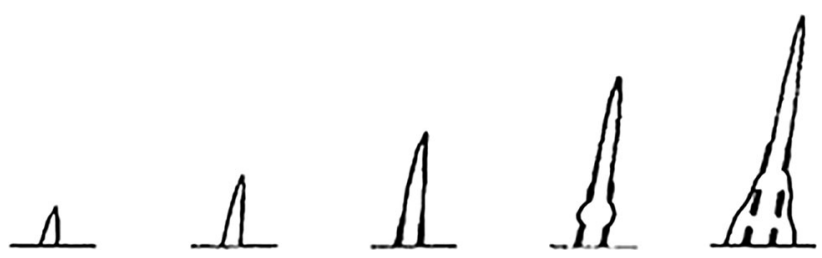

Fig. 5-Sketch of formation of upper bainite according to Hultgren. ${ }^{[14]}$

by diffusion to a retained part of the same slab of austenite.

The ghost lines between the original, thin plates of ferrite are difficult to see in the initial magnification but are well visible at higher magnification in the insert of Figure 4. Without a TEM study one can only speculate about the nature of the ghost lines and it should be noted that there is a wealth of other details with similar visibility. These objects could hardly be carbide particles, maybe clusters of some sort in combination with dislocations.

\section{B. Formation of Cementite}

In 1947 Hultgren $^{[14]}$ described the formation of bainite with a series of sketches, Figure 5, in connection with a microscopic investigation of the isothermal transformation of steels. He illustrated that the occurrence of cementite in contact with the primary plate of ferrite stimulates the flat ferrite/austenite interface to advance between cementite particles and thus to turn more curved. Comparison with the lowest plate in Figure 6 indicates that Hultgren was correct even with the last sketch, which illustrates that cementite can get isolated from contact with austenite. The short, almost vertical plate in Figure 6 illustrates that the plate initially consisted of only what is now situated below the band of carbides. The specimen in Figure 6 was transformed for 6 seconds at $773 \mathrm{~K}\left(500{ }^{\circ} \mathrm{C}\right)$.

The formation of cementite in the interspaces between parallel plates of ferrite in upper bainite was examined in some detail in the present study and will be described from the following basic understanding. Below the eutectoid temperature, cementite can normally nucleate at austenite/ferrite interfaces and develop eutectoid colonies of pearlite by cooperative growth with ferrite but this did not normally happen in the feathery structures. The reason may be that pearlite can form only if none of the phases has a special orientation relationship to the austenite, which favors coherent interfaces ${ }^{[15]}$ and that is the case for acicular ferrite. 
Figure 7 is from 1 second at $873 \mathrm{~K}\left(600{ }^{\circ} \mathrm{C}\right)$ and the transformation of austenite started with a number of parallel plates of ferrite originating from a prior grain boundary, a piece of which is seen close to the lower left corner. Close to the grain boundary, the interspaces gradually turned thinner by thickening of the plates and the plates finally merged and formed a complete layer, covering the prior grain boundary. During that process, the carbon content of the austenite increased locally and cementite may have nucleated somewhere on the ferrite/ austenite interface. It looks as if the cementite particles then became isolated from contact with austenite. In contrast, ordinary pearlite grows with both eutectoid phases in contact with austenite and pearlite in the process of transforming an austenite band is seen at the upper, right corner. At lower magnification it was evident that it originated from outside this group of ferrite plates.

Very close to the left-hand side of the micrograph in Figure 7 there is an elongated cementite particle that

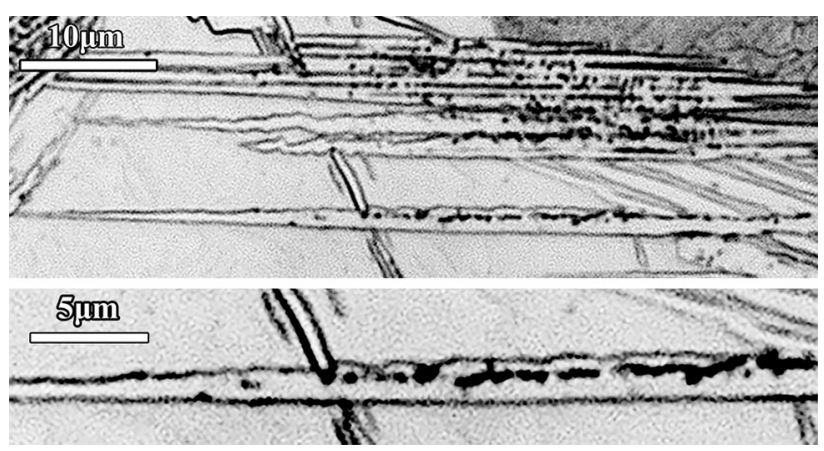

Fig. 6- LOM of FeSiC alloy after $6 \mathrm{~s}$ at $773 \mathrm{~K}\left(500{ }^{\circ} \mathrm{C}\right)$, showing white plates of ferrite with black particles of cementite. The small vertical plate indicates that the top layer of ferrite on the lower plate was formed last.

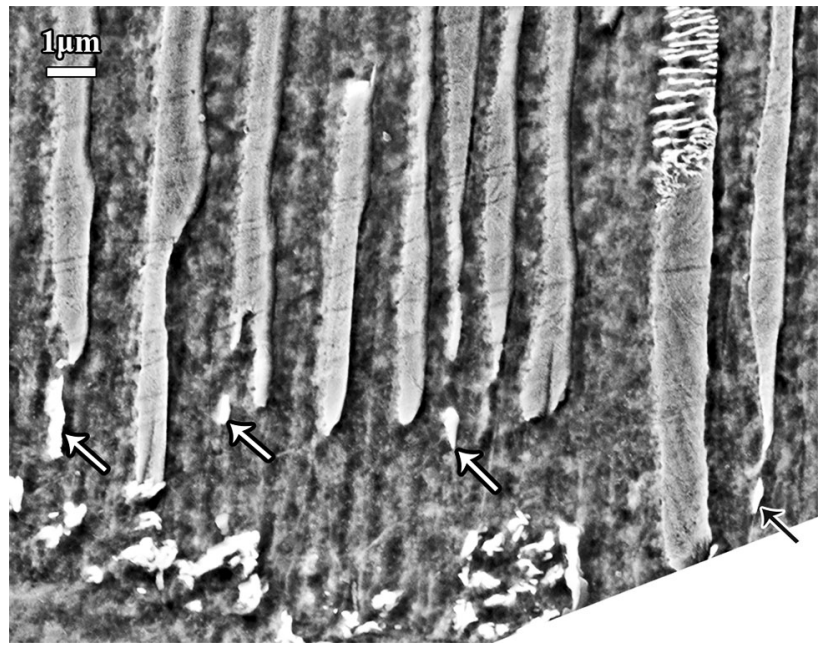

Fig. 7-SEM of feathery bainite close to austenite grain boundary visible close to lower left corner. FeSiC alloy after $1 \mathrm{~s}$ at $873 \mathrm{~K}$ $\left(600{ }^{\circ} \mathrm{C}\right)$. White particles are cementite, gray bands are austenite, and dark background is ferrite. Lower end of some austenite bands is being transformed to ferrite due to approaching cementite particles. seems to have caused the low part of the austenite band to transform to ferrite. It is interesting that the austenite band is transforming to ferrite above the cementite particle without direct contact to the carbide particle. A small cementite particle seems to have had a similar effect in the third interspace from the left without direct contact to the austenite and in the sixth interspace there is a small cementite particle that seems to grow into the next interspace to the right without direct contact.

Considering the fact that the two-dimensional micrograph gives incomplete information, it is suggested that these three cementite particles are in fact parts of irregular fingers extending from particles visible closer to the prior grain boundary. Those cementite particles would thus have been able to stay in a restricted contact to the austenite and thus continue to grow upwards. It is an interesting possibility that, given more time, each particle transforming an austenite band would penetrate further into the interspace and eventually transform its whole length. The complete transformation of an interspace would then depend on the formation of a single particle of cementite even without a pearlitic reaction.

Chemically, this would be a eutectoid reaction of austenite to ferrite and cementite but it is of a degenerate kind. ${ }^{[15]}$ It should be noted that no cementite has yet nucleated on the broad faces of the ferrite plates in Figure 7, supposedly because those interfaces are partially coherent and have low energy. As illustrated by the lower ends of the fourth and fifth austenite band, the ferrite/austenite interface is there curved and would not be coherent. That would be favorable for nucleation of cementite.

The rate of transformation is higher at $823 \mathrm{~K}$ $\left(550{ }^{\circ} \mathrm{C}\right)$ and after 1 second the transformation has proceeded far into some of the austenite bands, which can be seen in Figure 4. It is interesting that one can often find untransformed bands of austenite that are neighbors to transformed ones. This is more clearly shown in Figure 8 from 2 seconds at $673 \mathrm{~K}\left(400{ }^{\circ} \mathrm{C}\right)$. That may be taken as an indication that the transformation of an austenite band depends on a process that is not very frequent. It may depend either on the start of a degenerate eutectoid transformation close to the grain boundary, which was described above, or on an unusual nucleation event on a broad face of a plate some distance away from the prior grain boundary. Between the remaining bands of austenite in Figure 8 there have been several bands of austenite, which have been transformed and now contain cementite particles that are mostly elongated in the direction of a prior austenite band, which is typical of upper bainite.

The series of micrographs from partially transformed specimens from $823 \mathrm{~K}, 773 \mathrm{~K}$, and $673 \mathrm{~K}\left(550{ }^{\circ} \mathrm{C}\right.$, $500{ }^{\circ} \mathrm{C}$, and $400{ }^{\circ} \mathrm{C}$ ) in Figure 9 illustrates that there are no main differences of the microstructure with temperature. They were all taken from areas where some austenite bands in interspaces have shrunk to thin slabs and others have transformed more or less completely to ferrite and cementite, usually as elongated particles. Austenite slabs as well as cementite particles are white and are not always easy to distinguish. The cementite 


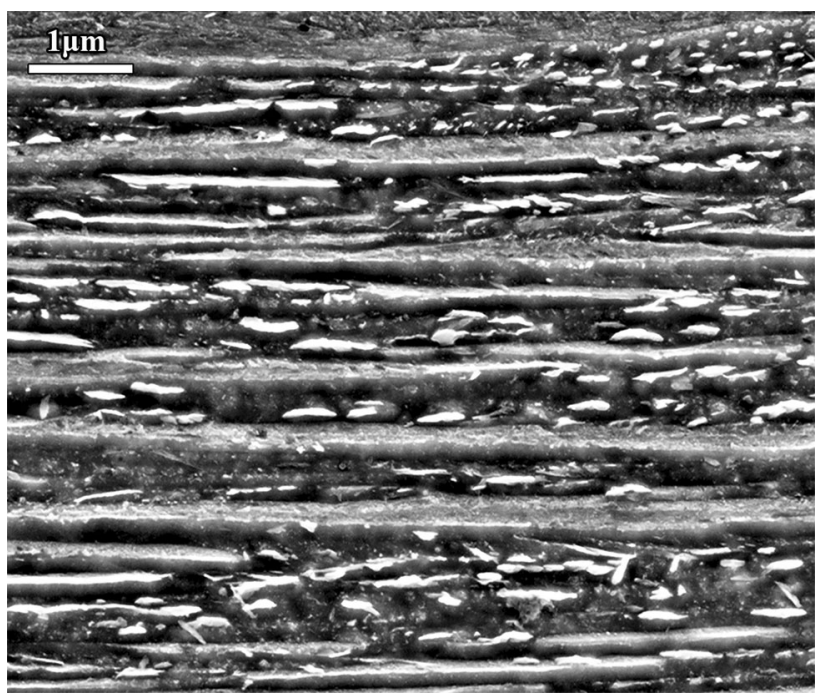

Fig. 8- SEM of feathery bainite in FeSiC alloy after $2 \mathrm{~s}$ at $673 \mathrm{~K}$ $\left(400{ }^{\circ} \mathrm{C}\right)$. Elongated cementite particles were formed by decomposition of prior bands of austenite between plates of ferrite. Some bands of austenite are not decomposed and are now gray bands of martensite and possibly retained austenite when white.

particles are more irregular and much less elongated. Figure 10 is from 2 seconds at $573 \mathrm{~K}\left(300^{\circ} \mathrm{C}\right)$ and shows only slightly elongated cementite particles in a background of ferrite, mainly plate ferrite. Their acicular nature is revealed by the distribution of the cementite particles. A prior unit of martensite can be seen in the upper, left corner and its cementite particles have the shape and orientations typical of tempered martensite. It is evident that the $M_{\mathrm{S}}$ temperature was above the holding temperature of $573 \mathrm{~K}\left(300{ }^{\circ} \mathrm{C}\right)$ and bainite in Figure 10 has been growing between martensite units.

The observations, discussed so far, can be explained as the result of a degenerate eutectoid transformation. A more unusual observation should also be considered. Figure 11 is a magnification of an area to the left of the area that was magnified in Figure 4. This slab has transformed to a mixture of ferrite and white cementite particles, some of which are small platelets. The fact that the platelets occur in different directions proves that they have nucleated individually and it raises the question why nucleation of cementite was not equally frequent in all the austenite slabs when reaching the same high carbon content.

\section{Formation of Eutectoid Colonies}

For thicker bands of austenite the transformation may be radically different. Even if the eutectoid reaction could spread rapidly along the flat ferrite/austenite interfaces in a thick band of austenite, it would then proceed more slowly into the austenite as a rather cooperative eutectoid reaction. Two examples from 2 seconds at $773 \mathrm{~K}\left(500{ }^{\circ} \mathrm{C}\right)$ are given in Figure 12. At the top of Figure 12(a) there is a thin ghost line separating two merged plates and below a thin slab of austenite (white) there is another plate. All these have
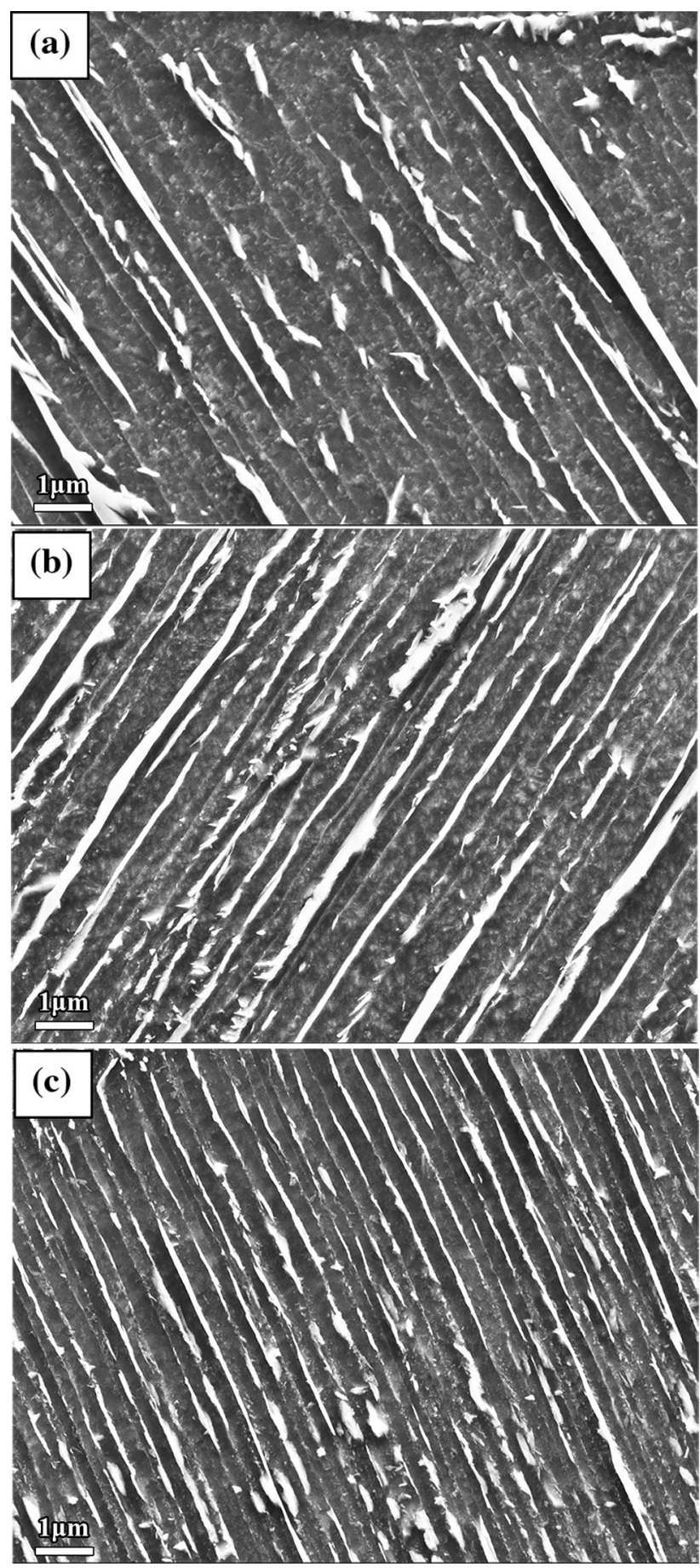

Fig. 9-SEM of typical microstructures of feathery bainite with only some of the prior austenite bands completely decomposed. The retained austenite formed white bands and sometimes very thin slabs. There is very little martensite. (a) $1 \mathrm{~s}$ at $823 \mathrm{~K}\left(550{ }^{\circ} \mathrm{C}\right),(b) 2 \mathrm{~s}$ at $773 \mathrm{~K}\left(500^{\circ} \mathrm{C}\right),(c) 2 \mathrm{~s}$ at $673 \mathrm{~K}\left(400^{\circ} \mathrm{C}\right)$.

rather flat interfaces. Below a wide unit of austenite (later on mainly transformed to martensite) there is a fourth plate of ferrite and it has a bulge on its lower side, extending into another wide unit of austenite. That bulge contains cementite particles and it seems to be caused by a eutectoid transformation. To the right in the 


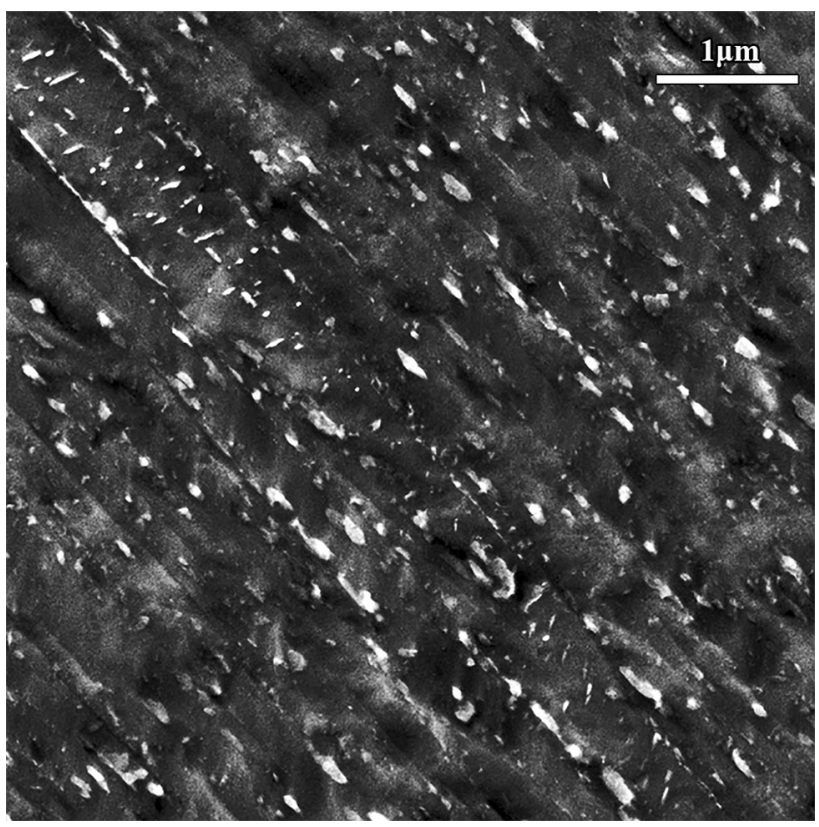

Fig. $10-\mathrm{SEM}$ of $\mathrm{FeSiC}$ alloy after $2 \mathrm{~s}$ at $573 \mathrm{~K}\left(300{ }^{\circ} \mathrm{C}\right)$. Etched according to Vilella. A strong contrast was used to emphasize the white cementite particles. Tempered martensite in the upper left corner.

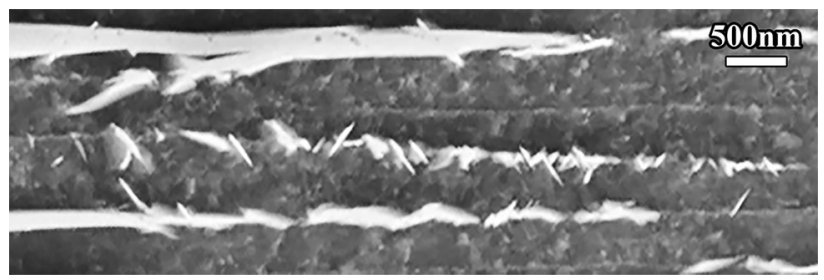

Fig. 11-SEM at higher magnification of area just to the left of the white rectangle in Fig. 4. The prior austenite band in the middle has decomposed to ferrite and cementite particles, mostly platelets.

bulge there are three cementite platelets that seem to have contact with the austenite and together with the ferrite they have a common growth front against the austenite. It is proposed that this is a sign of a cooperative eutectoid mechanism and the cementite-free ferrite represents the plate before the eutectoid transformation started. That part of the plate had already thickened by diffusion of carbon into the remaining austenite because it certainly lengthened with a sharp tip as demonstrated by the plate below the two merged plates. The thickening then accelerated on the lower side by the eutectoid transformation.

Figure 12(b) contains a thick plate of ferrite and its central region is free of cementite. It is again proposed that it represents the plate before cooperative eutectoid transformation started on both sides. Figure 13(a) is from 2 seconds at $673 \mathrm{~K}\left(400^{\circ} \mathrm{C}\right)$ and has similar examples and the best one concerns the largest band of austenite. It is suggested that it was initially larger and a thick layer was later transformed to a eutectoid colony, which was identified by painting it white in Figure 13(b). The original thickness is here shown with
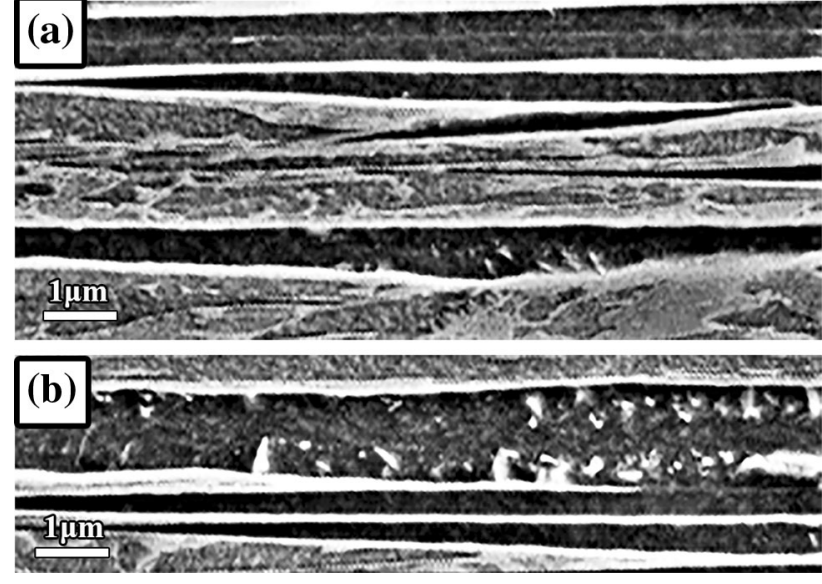

Fig. 12-SEM of feathery bainite in $\mathrm{FeSiC}$ alloy after $2 \mathrm{~s}$ at $773 \mathrm{~K}$ $\left(500{ }^{\circ} \mathrm{C}\right)$. Ferrite is black, cementite particles are white, bands of austenite are white, and martensite is in different shades of gray. (a) Eutectoid colony forming a bulge on the lower side of a plate of ferrite. (b) Thick band of ferrite with a plate free of cementite in the middle, surrounded by eutectoid layers. The lower layer is in the process of transforming a band of austenite/martensite.

the white paint and the gray austenite/martensite. Sometimes a band of austenite is not thick enough for a cooperative eutectoid but almost. The elongated cementite particles obtained with thinner austenite slabs may then be replaced by smaller particles but often with more than one beside each other as shown in Figure 13(c).

Figure 14 is from the same specimen and shows four widely spaced plates, three of which are covered with eutectoid mixtures of ferrite and cementite on both sides. In this case it is fairly easy to recognize the thin cementite-free plates of ferrite in the middle of each unit. Figure 15 is from the preceding paper and shows a plane of polish that was not in the main growth direction of the plates. It rather shows a cross section of a sheaf which contains plates of ferrite and eutectoid mixture of ferrite and cementite that fills the interspaces. Parts of ferrite plates are sticking out into austenite on both sides of the sheaf. Close to the upper right corner there is a eutectoid colony, which is advancing on the upper side of a plate of ferrite and in the middle there is another eutectoid colony doing the same.

The FeSiC alloy was used for all the micrographs so far. Eutectoid colonies were also found in the other two alloys. Figure 16 is from the $\mathrm{FeMnC}$ alloy with 0.5 mass pct $\mathrm{Mn}$ and the second thickest band of austenite to the left is being transformed by a eutectoid transformation starting about a quarter of the way to the right-hand side. It has been completely transformed before reaching that side. The insert to the right in Figure 17 demonstrates that a plate of pure ferrite has been covered by a eutectoid layer on the left-hand side. The insert to the left indicates that a prior austenite band between two plates of ferrite has transformed to a eutectoid mixture. It is also interesting that the thickening of the plates behind the tips is usually very gradual but then some plates thicken rather abruptly due to the appearance of cementite. 

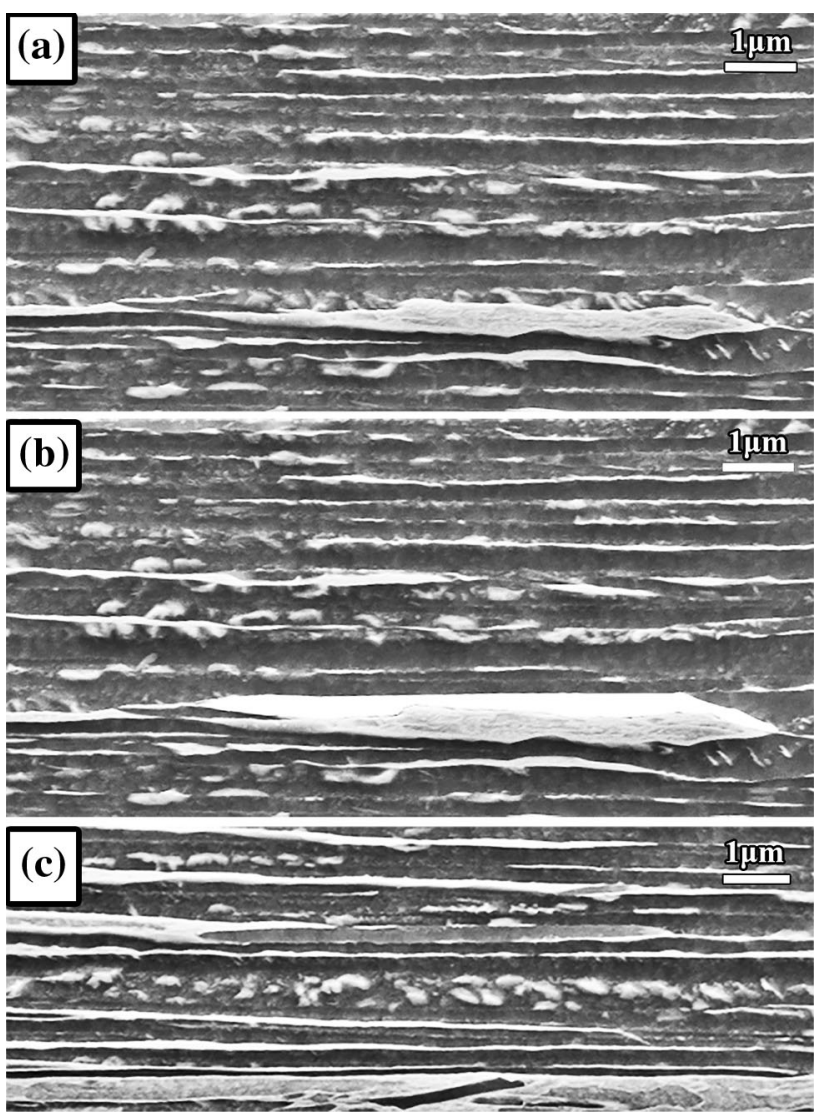

Fig. 13-SEM of FeSiC alloy after $2 \mathrm{~s}$ at $673 \mathrm{~K}\left(400{ }^{\circ} \mathrm{C}\right)$, illustrating the decomposition of a thick austenite band. (a) Present microstructure. (b) Same micrograph but with an area of austenite, just decomposed by eutectoid reaction, painted white. Together with the gray band of austenite/martensite it illustrates the size of the austenite band before the eutectoid transformation started. (c) Band of cementite particles side by side, formed by eutectoid decomposition of a former band of austenite (just below the middle).

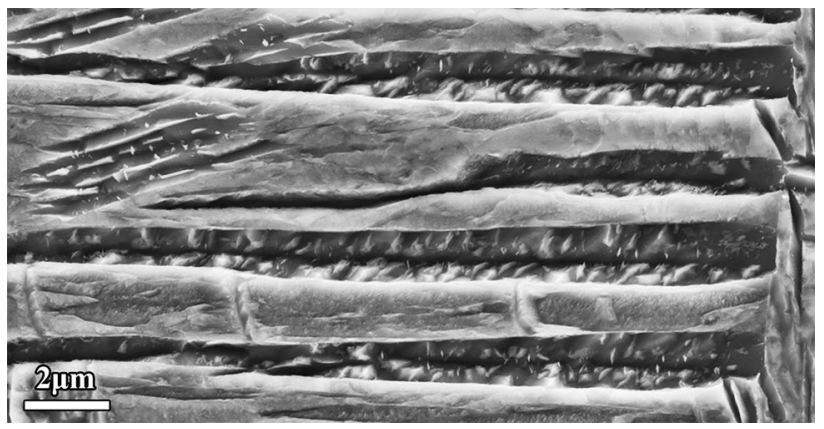

Fig. $14-\mathrm{SEM}$ of $\mathrm{FeSiC}$ alloy after $2 \mathrm{~s}$ at $673 \mathrm{~K}\left(400^{\circ} \mathrm{C}\right)$, showing very thin plates of ferrite, free of cementite particles but surrounded by eutectoid layers.

The microstructure of the FeMnSiC alloy with 0.5 mass pct each of silicon and manganese is also rather similar but parallel platelets, which occurred in the other two alloys, were more frequent. In some areas they were even predominant as in Figure 18. Figure 19(a) from the same specimen gives a three-dimensional impression by deep etching and indicates that

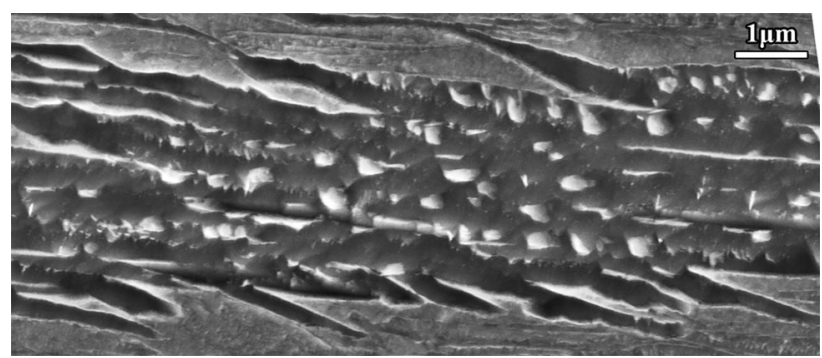

Fig. 15-SEM of FeSiC alloy after $2 \mathrm{~s}$ at $673 \mathrm{~K}\left(400{ }^{\circ} \mathrm{C}\right)$ illustrating how eutectoid colonies are in the process of covering the surface of ferrite plates.

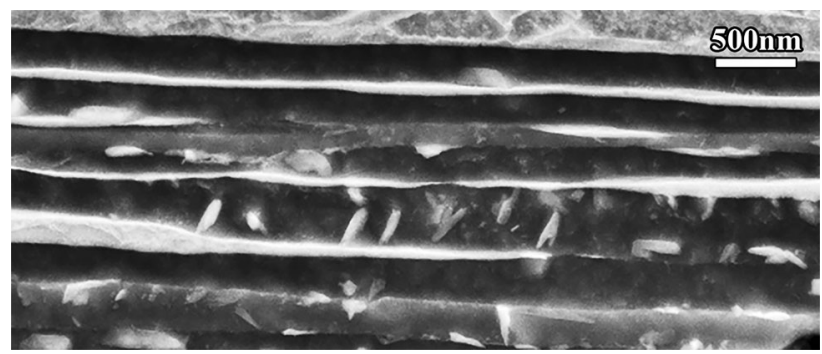

Fig. 16-SEM of FeMnC alloy after $2 \mathrm{~s}$ at $673 \mathrm{~K}\left(400{ }^{\circ} \mathrm{C}\right)$, showing austenite bands of various thickness, either white or transformed to martensite. In the lower part, a eutectoid colony is decomposing a band of austenite.

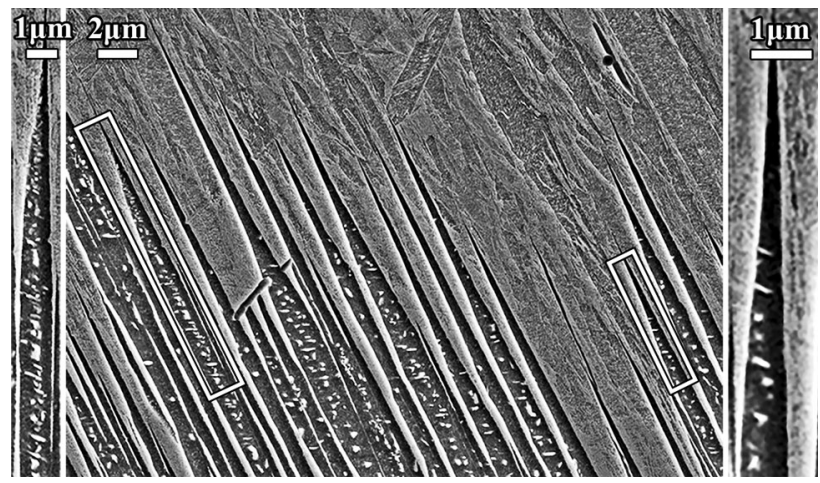

Fig. 17-SEM of growth front of feathery bainite in FeMnC alloy after $2 \mathrm{~s}$ at $773 \mathrm{~K}\left(500{ }^{\circ} \mathrm{C}\right)$. Magnified plates are inserted on the sides, the one to the right showing a cementite-free plate of ferrite covered by a eutectoid layer and the one to the left showing two cementite-free plates of ferrite with a eutectoid layer in between.

the cementite particles are really platelets and not needles. It was unfortunate that etching in nital and picral left both cementite and the thin austenite slabs with high carbon content without attack. They thus appear white and are difficult to distinguish. Figure 19(b) illustrates that the special etching reagent for cementite did not help much because it attacked both. Nevertheless, Figure 19(b) demonstrates that cementite and ferrite can have a common growth front with both phases in contact to the austenite as a cooperative eutectoid should.

All these observations show clearly that the eutectoid transformation is active in the formation of upper bainite. This supports the proposal that elongated 


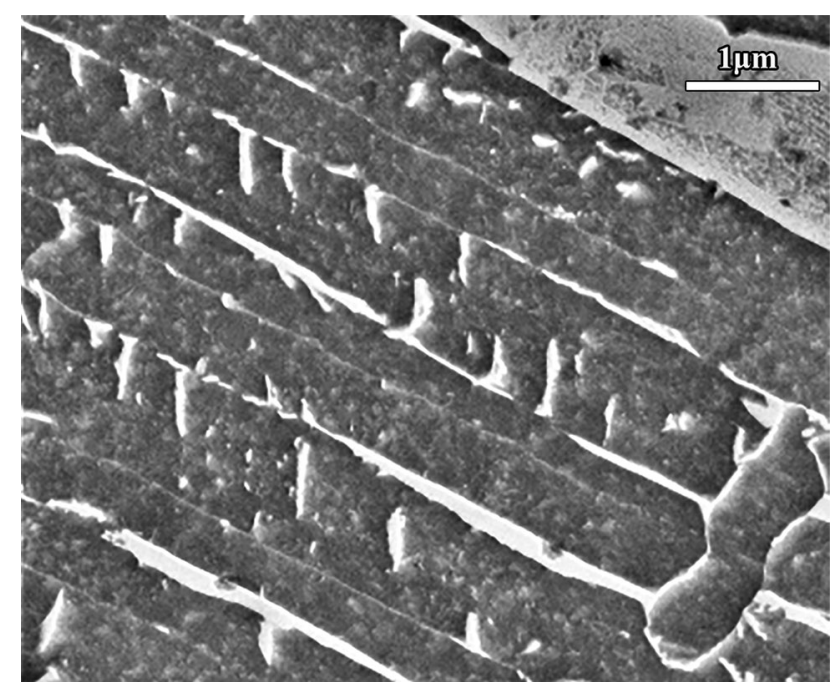

Fig. 18-SEM of feathery bainite in FeMnSiC alloy after $6 \mathrm{~s}$ at $773 \mathrm{~K}\left(500{ }^{\circ} \mathrm{C}\right)$, showing eutectoid decomposition resulting in cementite lamellae, which are all parallel. White lines or band are austenite.

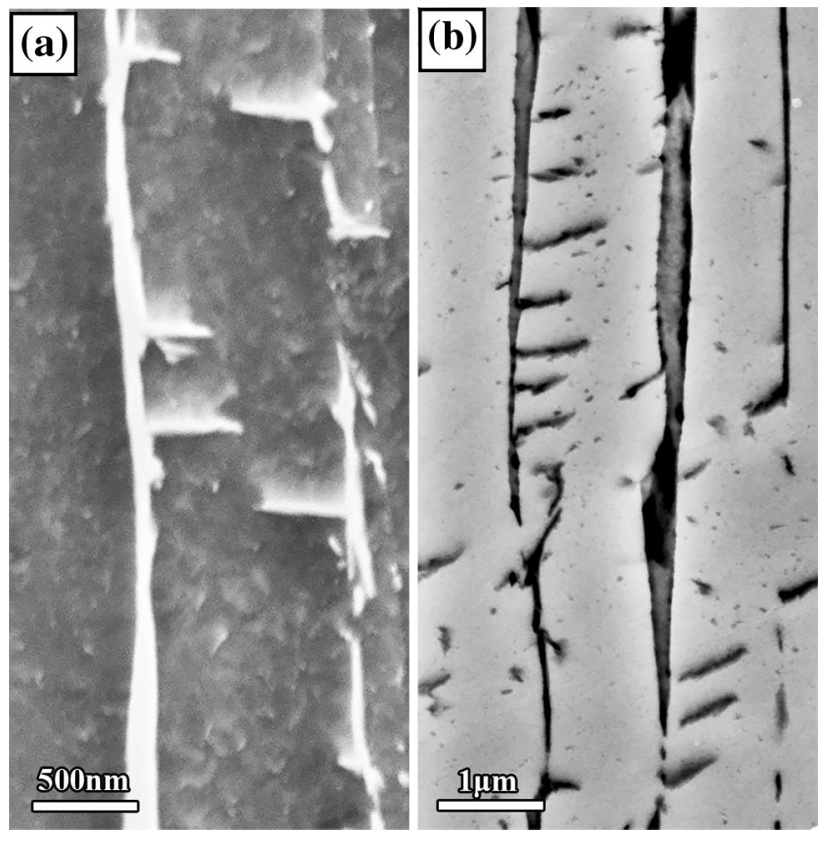

Fig. 19-(a) Same specimen as Fig. 18. Cementite particles looking like platelets and not needles. (b) Same but with cementite etching. Both cementite and thin austenite are black. Cementite particles have contact with austenite.

particles of cementite, as those in Figure 8, are also formed by a eutectoid transformation but of the degenerate kind. Where the slabs of austenite are thicker, a more cooperative eutectoid transformation can develop. A colony of pearlite generally consists of two intertwined crystals, one of each phase, ${ }^{[15]}$ and that seems to be the rule for eutectics and eutectoids and should also apply to the eutectoid stage of bainite formation. On the other hand, it seems difficult to deny that nucleation of new platelets of cementite in bainite may play some role, e.g., in the formation of the long row of platelets with various directions in the middle of Figure 11.

The eutectoid layers presented so far were less than $1 \mu \mathrm{m}$ thick. It would have been interesting to observe considerably thicker layers. However, longer heat treatments would also increase the overall degree of transformation and it could then be difficult to identify such regions. As an alternative, an intragranular plate, which happened to be sectioned almost parallel to its broad faces, was instead examined. It was found in the same specimen as Figures 18 and 19(a) and is shown in Figure 20. The pattern of the eutectoid mixture emphasizes the role of parallel cementite platelets.

\section{Formation of Bainite Below $M_{S}$}

Martensite started to form somewhere between $673 \mathrm{~K}$ and $623 \mathrm{~K}\left(400{ }^{\circ} \mathrm{C}\right.$ and $\left.350{ }^{\circ} \mathrm{C}\right)$ and seemed to prevent an extension of the study to lower temperatures. However, it was found that the transformation in the present alloys was so rapid that considerable transformation could occur already during cooling in the metal melt. That is why the inner part of the feathers in Figure 2 from $573 \mathrm{~K}\left(300{ }^{\circ} \mathrm{C}\right)$ has a coarser structure that after etching appears dark in LOM at low magnification. This effect was even more pronounced in specimens treated well below the $M_{\mathrm{S}}$ temperature. The LOM micrograph in Figure 21 is from $473 \mathrm{~K}\left(200{ }^{\circ} \mathrm{C}\right)$ and demonstrates that the coarse structure in the feathers gradually developed into a very fine structure, which in LOM appears almost unaffected by etching. It was finally stopped when martensite formed. The result was similar for a specimen with a holding temperature of $573 \mathrm{~K}\left(300{ }^{\circ} \mathrm{C}\right)$ but it was there observed that some bainite, which had continued to grow between the first units of martensite, had finally been stopped by martensite that did not show signs of being tempered at $573 \mathrm{~K}$ $\left(300{ }^{\circ} \mathrm{C}\right)$, Figure 22 . Tempered martensite is easy to recognize as demonstrated in the upper left corner of Figure 10 from the same specimen. It is concluded that the martensite shown in Figure 22 had formed during the final quench from $573 \mathrm{~K}\left(300{ }^{\circ} \mathrm{C}\right)$. Accepting that the growing bainite plates were stopped by formation of martensite, then these plates must have been growing when the quench started, i.e., at a temperature close to $573 \mathrm{~K}\left(300{ }^{\circ} \mathrm{C}\right)$. This bainite resembles upper bainite from higher temperatures and has not turned similar to lower bainite. The acicular nature is still pronounced. The reason is a strong tendency to form ferrite plates.

Singh et al. ${ }^{[16]}$ studied the thickness of ferrite plates in so-called carbide-free bainite in steels with 0.10 to 0.46 mass pct C. For the present alloy, it was evaluated from the closest spacing of ferrite plates, defined as the distance between the tips of neighboring plates, which is comparable to the final thickness of the ferrite plates because the fraction of cementite is small. Both results are presented in Figure 23 and are comparable over the whole temperature range. Without analyzing the possible effects of the difference in carbon contents, it was taken as further support for the assumption that the bainite in Figure 21 actually formed at an approximate temperature of $573 \mathrm{~K}\left(300^{\circ} \mathrm{C}\right)$. 


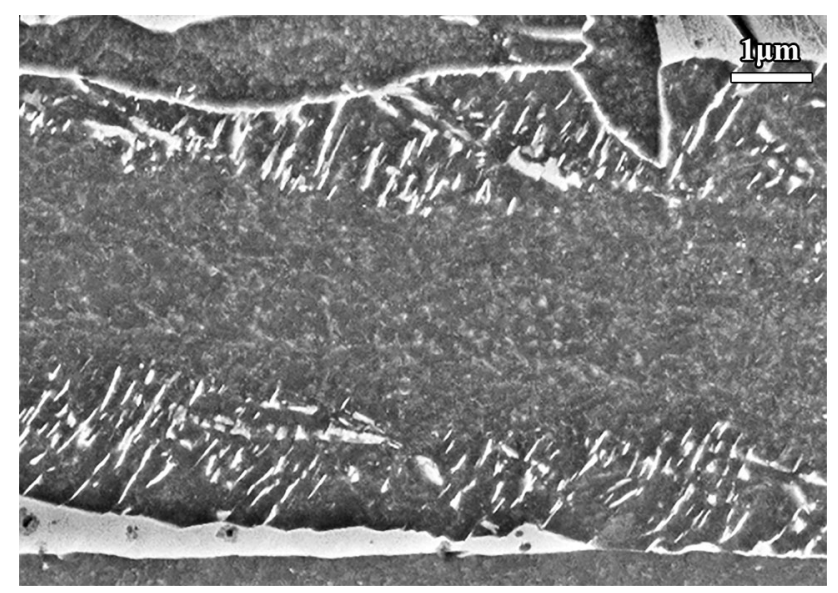

Fig. 20-SEM of oblique section through an intragranular plate of ferrite in FeMnSiC alloy after $6 \mathrm{~s}$ at $773 \mathrm{~K}\left(500{ }^{\circ} \mathrm{C}\right)$. Thin eutectoid layers on a cementite-free plate of ferrite appear much thicker than they are, due to oblique sectioning. Eutectoid layers contain many platelets.

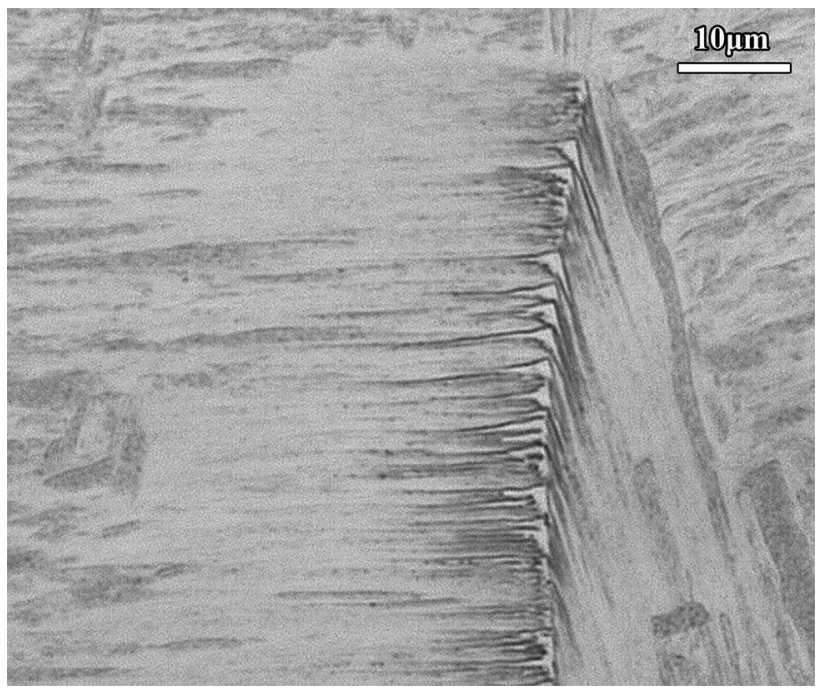

Fig. 21-LOM of feathery bainite in FeSiC alloy after $2 \mathrm{~s}$ at $473 \mathrm{~K}$ $\left(200{ }^{\circ} \mathrm{C}\right)$. Primary ferrite shaped as chevrons formed on a grain boundary above the holding temperature. They continued to grow and gradually turned finer as the holding temperature was approached.

\section{DISCUSSION}

\section{A. Sketches of Upper Bainite}

An attempt was made to rationalize the above observations by accepting that the transformation of the remaining austenite between ferrite plates occurs with a eutectoid reaction. A series of idealized sketches of various cases is presented in Figure 24 and in a negative print in Figure 25 for direct comparison with the SEM micrographs presented here. Ferrite is there black and cementite and austenite with high carbon content are white. Each sketch illustrates the microstructure in a specimen after interrupted transformation. The vertical length scale is much compressed and, compared to the horizontal length scale, the top parts should be

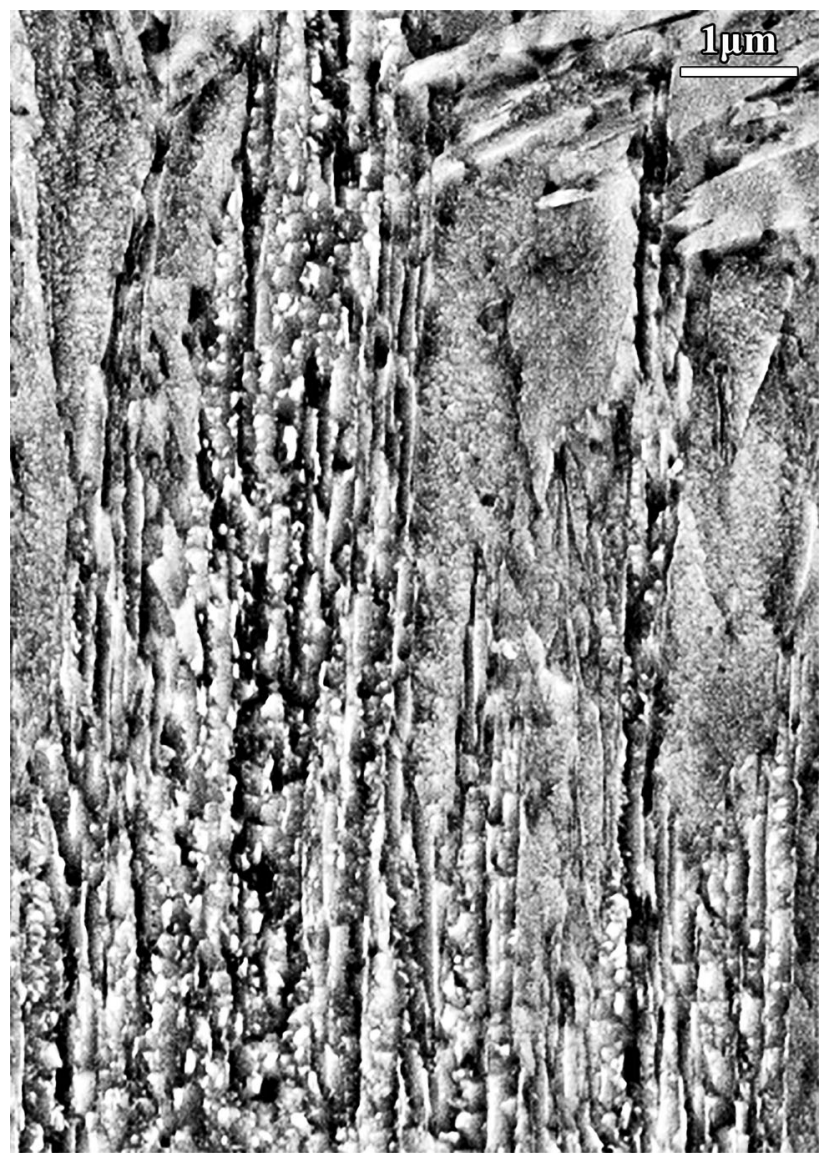

Fig. 22-SEM of FeSiC alloy heat treated for $2 \mathrm{~s}$ in metal bath of $573 \mathrm{~K}\left(300{ }^{\circ} \mathrm{C}\right)$. A sheaf of very fine plates of ferrite (black) with white cementite particles in between have grown upwards in the middle and been stopped by martensite (background of diffuse pattern of gray and black).

much longer than shown here. Sketch (a) illustrates that a plate of ferrite grows with a tip in the fastest growth direction as in Figure 3. It immediately starts to thicken and the remaining austenite in the interspace between two neighboring plates gets thinner until a high critical carbon content is reached. Then it will not be transformed to martensite on quenching and will not be attacked by nital due to the high carbon content. It may look as white as cementite in SEM. That is illustrated by shades of white in Figure 25 and automatically it will be dark in Figure 24. The situation at the lower end of the sketch will apply all the way back to the beginning of the plate close to the grain boundary.

When cementite appears, it will start the eutectoid transformation of the austenite and the result will depend on the thickness of the austenite region and thus on how close it approaches the tips. Cementite has formed in (b) but the reaction front is far from the tips and the plates have almost stopped thickening. The remaining slab of austenite is thin and carbon rich. First there will be just one finger of cementite growing into the interspace and transforming the austenite as illustrated to the very left in Figure 7. As already discussed, the finger is not straight and in each plane of polish only some pieces will show up. In (c) the remaining austenite 


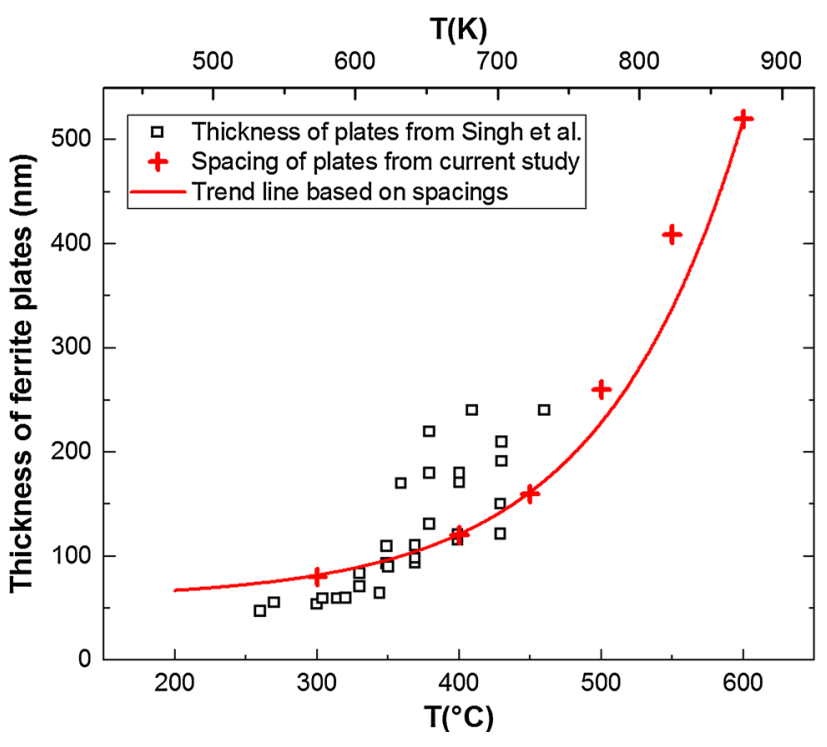

Fig. 23 - Comparison of the closest spacings between plates of ferrite in present study $(+)$ and thickness of ferrite plates in so-called carbide-free bainite (published by Singh et al. ${ }^{[16]}$ ).

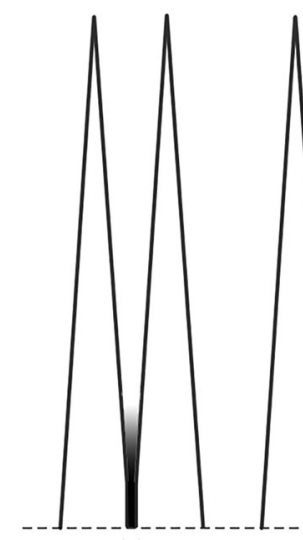

(a) (b)

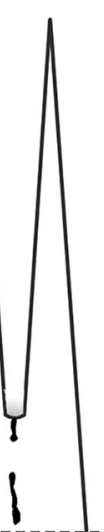

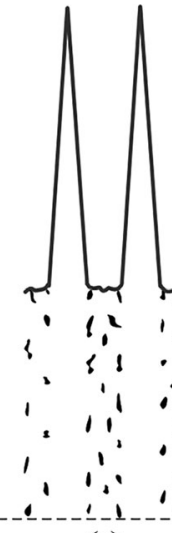

(c)

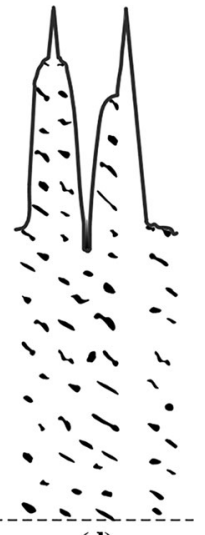

(d)
Fig. $24-$ Schematic illustration of the effect of different modes of the eutectoid transformation of austenite between two parallel plates of ferrite. The vertical scale has been much compressed. Ferrite is white and cementite is black. Austenite with different degrees of carbon enrichment is illustrated with different shades of gray. (a) No cementite is available and thickening of ferrite plates can continue. Remaining austenite gets rich in carbon. (b) Cementite is finally available and starts a eutectoid reaction of a degenerate nature. $(c)$ The eutectoid reaction is able to transform austenite of lower carbon content. The eutectoid has space for developing more cooperative growth. (d) The eutectoid reaction is able to transform austenite of even less carbon. It can cover the side of a plate.

band is thicker at the reaction front and there is more space for the reaction to be more cooperative. The growth direction of the cementite crystal can vary and the cementite particles, visible in the plane of polish, are not positioned in a line. This was illustrated in Figure 13(c). In (d) the reaction has reached even closer to the tips and has spread over the flat sides of the plates as illustrated in Figure 14. There is now room for layers of cooperative eutectoid. The layer on the right-hand plate is an illustration of the upper right-hand corner of Figure 15.

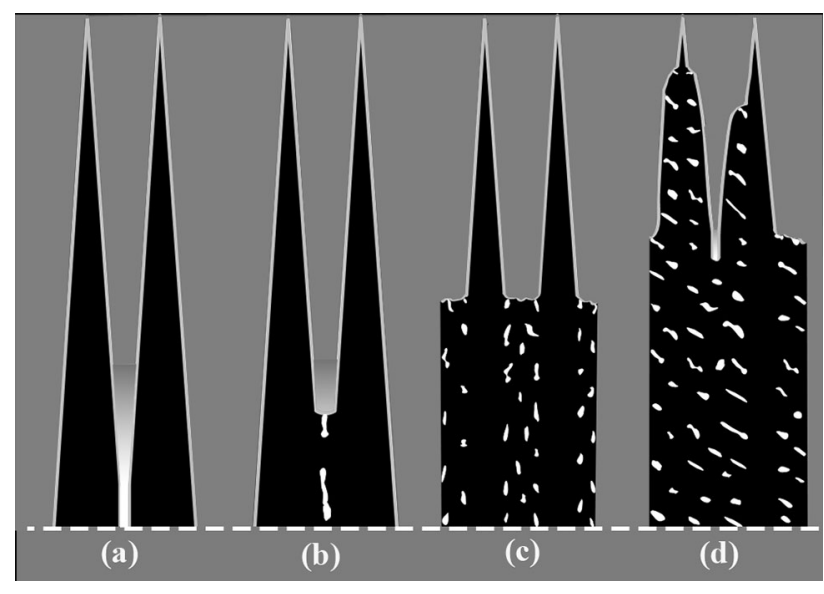

Fig. 25-Negative print of Fig. 24 to resemble SEM micrographs.

When formed as part of a cooperative eutectoid, cementite may develop as platelets with a large angle to the main growth direction of the plates and rather perpendicular to the growth front of the eutectoid. It should be emphasized that the variation from Figures 24(a) to (d) may depend on several factors such as time of interruption, temperature, carbon content of alloy, and alloying elements and also on combined effects of these. It should also be emphasized that the internal structure of the eutectoid layer can vary considerably between different regions of a specimen. Figures 18 and 20 make a drastic example. It may possibly depend on differences in the orientation relationships between the three phases involved.

\section{B. Cooperative Growth in Upper Bainite}

By growing side by side behind a common growth front, two eutectic or eutectoid phases can cooperate by optimizing the effective diffusion distance. The result will usually be a rather regular two-phase mixture, such as pearlite. On the other hand, for special orientation relationships of ferrite in $\mathrm{Fe}-\mathrm{C}$ alloys, the result will instead be upper bainite, which is composed of ferrite and cementite and, chemically, it is thus a eutectoid mixture. When studied in more detail it is realized that there are at least two stages of transformation to upper bainite, the proeutectoid precipitation of ferrite plates and the final transformation of the remaining austenite in the interspaces to a mixture of ferrite and cementite. As described in Section III-B, the interspaces in upper bainite will typically transform to ferrite and elongated cementite particles without a well-defined common growth front and the resulting microstructure was regarded as a degenerate eutectoid.

In Section III-C it was described that, when the interspace is wide enough, the eutectoid reaction may be able to organize itself and to progress with a common growth front. That implies that the two phases cooperate. When this was observed by Hillert, ${ }^{[7]}$ he studied electron micrographs by Modin and Modin, ${ }^{[17]}$ made with plastic replica, which was the available technique in 1955. The micrograph is reproduced in Figure 26 with 


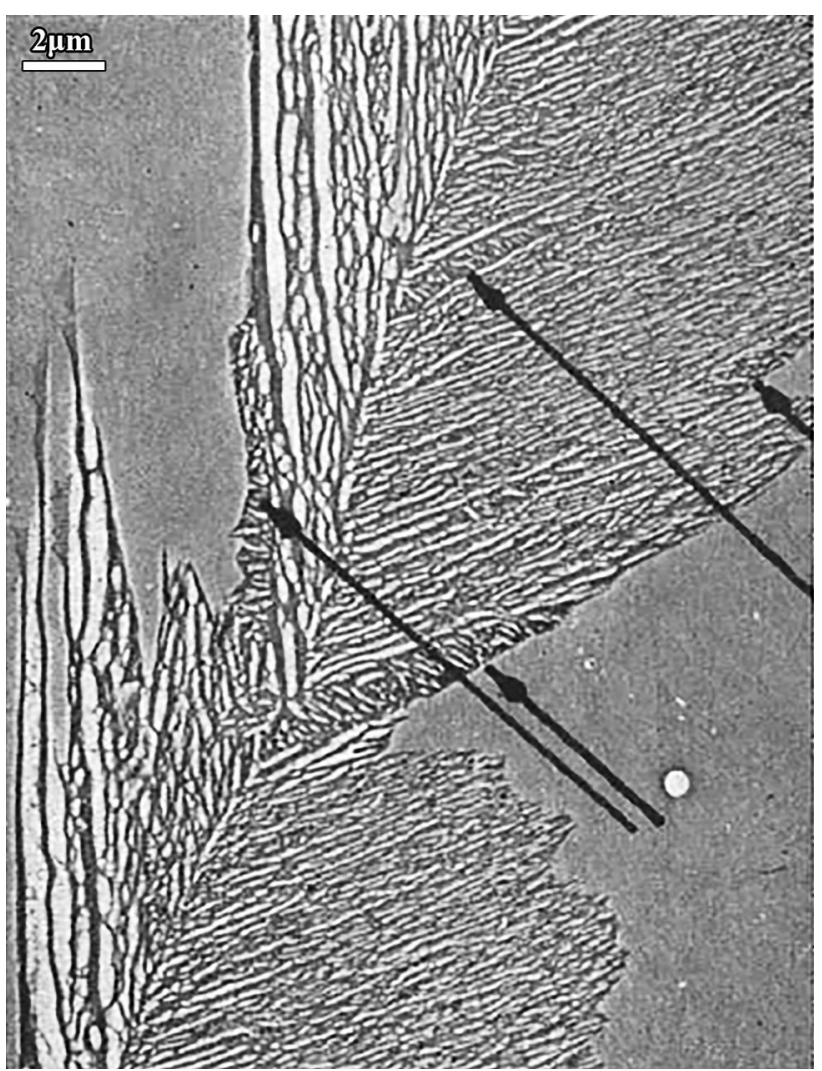

Fig. 26-Upper bainite in a steel with 0.86 mass pct $\mathrm{C}$ after $6 \mathrm{~s}$ at 773 K. From Ref. [17]. Arrows are added in Ref. [7] and indicate the presence of eutectoid colonies.

the arrows added by Hillert. He classified this micro-constituent as a cooperative eutectoid, which to him was an appropriate term because he published this observation together with his solution of diffusional growth of pearlite and with calculated shapes of the common growth front. In a subsequent paper he $\mathrm{h}^{[15]}$ emphasized that pearlite could not form if ferrite or cementite has such an orientation relationship to the austenite that it tends to form partially coherent interfaces of low energy to the austenite. This now raises a serious question. Even though the eutectoid colonies, observed in upper bainite, do not look as well organized as pearlite, one may wonder how any cooperation is possible when the ferrite constituent has the same crystalline orientation as the ferrite plates in the same area. Why does it not form plates protruding in front of the common growth front, e.g., in Figure 15, and why does it not form a facet on the upper side of the advancing colonies?

An explanation may be based on an in situ observation on a Fe-9 pet Ni-0.4 pet C alloy at $623 \mathrm{~K}\left(350{ }^{\circ} \mathrm{C}\right)$ by Ohmori et al. ${ }^{[18]}$ (Figure 6 in Reference 18). Sharp relief effects after 10 minutes revealed the presence of several thin plates of ferrite but some of them were covered by layers revealed by a less distinct relief called rumpling. After further 24 minutes those layers were much thicker. The authors explained that the distinct relief represented a plate of ferrite formed by a displacive process and the rumpling represented sideways growth of the same crystal but by a different process. In fact, similar observations, but not of the same quality, can be made on micrographs presented by Ko, ${ }^{[19]}$ Miodownik. ${ }^{[20]}$ It may further be mentioned that Le Houillier et al. ${ }^{[21]}$ with 0.63 mass pet $\mathrm{C}$ observed thin, parallel plates after 10 minutes at $673 \mathrm{~K}\left(400^{\circ} \mathrm{C}\right)$ and quench, which were covered with layers of a speckled constituent. After a controlled reheating to $633 \mathrm{~K}$ $\left(360{ }^{\circ} \mathrm{C}\right)$ and new quench, the layers have grown thicker (Figure 10 in Reference 21). It is an interesting possibility that those layers are eutectoid. It should be added that Ohmori et al. accepted the general idea that the second stage of upper bainite occurs by the precipitation of cementite from austenite, which has received carbon from the volume transformed to primary ferrite plates. Cementite can thus precipitate and more ferrite will form as the carbon content is lowered. This process seems to be widely accepted, e.g., by Sandvik ${ }^{[22]}$ and Tsuzaki et al. .23] $^{23]}$

In the preceding study, ${ }^{[1]}$ it was observed that the thickening of ferrite plates was sometimes accelerated locally and it was explained as a change of properties of the interface, which is normally expected to be partially coherent for a plate of ferrite. It is particularly interesting that the accelerated growth developed a bulge but on its front side there was no tendency to develop protrusions in the main direction of the plate. It is proposed that for some unknown reason the interface lost all or part of its coherency and behaved more as an incoherent interface with high mobility. This may be the same phenomenon that Ohmori et al. observed and it may be suggested that such a change of properties of the ferrite/ austenite interface can occur in the interspaces in upper bainite when cementite appears and stimulates ferrite to grow in new directions. That may have happened in Figure 6 when a ferrite plate penetrated a layer of cementite particles. It may be significant that the upper side of that ferrite plate is not as flat as the lower side.

In any case, it is suggested that the further growth of cementite, after its nucleation, may occur under various degrees of cooperation with ferrite, starting with a degenerate eutectoid reaction, which transforms thin slabs of austenite, and gradually developing a higher degree of cooperation as it continues to grow into thicker bands of austenite. However, it never develops the high degree of cooperation that is operative in pearlite.

It is worth mentioning that Tsuzaki et al. ${ }^{[23]}$ claimed that ferrite, formed in the first stage, does not thicken and ferrite, formed in the second stage, and belongs to a different variant. However, the fact that the ferrite in the plate and the subsequently thickened layer can have the same crystalline orientation is confirmed with EBSD in the current work as evident from the uniform color of ferrite plates in Figure 27(c). With TEM technique, Sandvik ${ }^{[22]}$ also observed same orientation relationship with respect to austenite for ferrite formed in both stages.

Cementite can often form as thin platelets or lamellae during the cooperative eutectoid transformation. As demonstrated by Figure 18, all cementite platelets seem to be parallel in a large area although they have formed 
in different austenite bands that would ideally be isolated from each other by plates of ferrite. It seems unlikely that they have developed from one common nucleus. The platelets may originate from many nuclei but all of the same crystalline orientation. This may be explained primarily by uniform orientations of ferrite and austenite in the whole region and additionally by assuming that all nucleation of cementite occurs in contact with both ferrite and austenite which was suggested by Sandvik ${ }^{[22]}$ who found that the carbide particles have a unique orientation relationship to bainitic ferrite.

\section{Nature of Upper and Lower Bainite}

A tight group of parallel plates of upper bainite was called sheaf by Aaronson and Wells ${ }^{[24]}$ who proposed that they form by repeated sympathetic nucleation of a new parallel plate of ferrite on the side of a previous plate. With one of three sketches, now reproduced as Figure 28, Oblak and Hehemann ${ }^{[25]}$ illustrated how a new subunit could add to the length of the sheaf. Sketch (a) depicts Widmanstätten plates formed under carbon diffusion, sketch (b) depicts upper bainite with subunits, and sketch (c) depicts lower bainite with another kind of subunits. A micrograph corresponding to sketch (c) is presented in Figure 11(a).

Zener $^{[5]}$ considered a possible deviation from equilibrium distribution of carbon across the advancing ferrite/ austenite interface and proposed increasing deviation with decreasing temperature. As already mentioned, in micrographs like Figure 26, Hillert ${ }^{[7]}$ observed that cementite in upper bainite had formed in two modes, normally by precipitation of elongated particles in narrow interspaces between parallel plates of ferrite but sometimes by a more cooperative eutectoid reaction where thicker volumes of austenite were available. $\mathrm{He}$ discussed whether this more cooperative mode would be favored by lower temperature. Some effort was now made to test this but the result was indecisive, which will soon be explained.

Matas and Hehemann ${ }^{[9]}$ gave an explanation of the difference between upper and lower bainite based on the diffusionless model, which predicts that the ferrite plates form with a high supersaturation of carbon. For lower bainite they proposed that the supersaturation in the ferrite should result in a fine precipitate of cementite inside the ferrite. For upper bainite there should be time for carbon to escape to the austenite in the interspaces and precipitate as elongated cementite particles. The acicular nature of bainite would thus be more visible. Today this seems to be the most widely accepted picture of the difference between lower and upper bainite.

It should be mentioned that platelets as those in Figures 18 and 19 are often been observed, e.g., by Ohmori et al. ${ }^{[26]}$ (Photo 8 in Reference 26). On the other hand, due to the lath-like shape of ferrite plates, they classified this as upper bainite and called it class BIII. They argued that the difference between upper and lower bainite should be based on the morphology of ferrite and not cementite. This has not always been accepted. For instance, Bhadeshia ${ }^{[27]}$ published a very similar micrograph (Figure 1 in Reference 27) and classified it as lower bainite because of the cementite morphology although it was from $708 \mathrm{~K}\left(435^{\circ} \mathrm{C}\right)$.

Figures 29(a) and (b) are presented in an attempt to describe the relation and difference of upper and lower bainite in terms of the eutectoid stage of formation of bainite. They are from 2 seconds at $673 \mathrm{~K}\left(400{ }^{\circ} \mathrm{C}\right)$ and illustrate a mixture of the two eutectoid morphologies of cementite in bainite. The whole area is filled with parallel plates of ferrite. Some of them are clearly visible because elongated cementite particles have precipitated between them. That reminds of upper bainite. Other areas seem to have a smooth background of ferrite with parallel platelets of cementite, e.g., the right-hand part of Figure 29(a). That reminds of lower bainite. However, the particles are arranged in rows, which separate plates of ferrite free of cementite, and they are not thicker than most of the other plates. The difference between areas seems to be due to the eutectoid reaction in the interspaces which sometimes degenerated as in upper bainite and sometimes occurred in a more cooperative manner but limited to the thin regions of prior interspaces. Probably, the whole microstructure of Figures 29(a) and (b) should be regarded as upper bainite according to Ohmori et al. ${ }^{[26]}$ due to the presence of parallel plates of ferrite in the whole volume. On the other hand, it would be regarded as lower bainite if there had been just a few plates of ferrite and there instead had been room for the cooperative eutectoid to transform wider volumes of austenite. It should be mentioned that already Pickering ${ }^{[28]}$ reported the simultaneous occurrence of upper and lower bainite near the transition temperature.

According to this picture, the microstructure of bainite is primarily controlled by three basic factors, the tendency to form ferrite plates, the tendency to form cementite in the presence of austenite and ferrite, and the tendency for the eutectoid reaction to turn cooperative. In practice, the result would depend on how various factors, e.g., temperature, carbon content, alloying elements, grain boundaries, inclusions etc., affect the basic factors. As an example, the terms upper and lower bainite refer literally to the effect of temperature as if it acted directly. Evidently, these terms are misleading for low-carbon contents and it would for instance be interesting to analyze the effects of temperature on the basic factors. Figures 10 and 22 showed that the parallel platelets of cementite, which were regarded as an effect of cooperative growth in Figure 28 from $673 \mathrm{~K}\left(400^{\circ} \mathrm{C}\right)$ were absent at $573 \mathrm{~K}\left(300^{\circ} \mathrm{C}\right)$, supposedly because the formation of ferrite plates was strong. No information was obtained on the possible effect of lower temperature on cooperative growth. The result was not unexpected because it has long been known that lower bainite does not form in low-carbon steels with less than 0.4 mass pct C. ${ }^{[29]}$ It seems logical that one would obtain lower bainite at $573 \mathrm{~K}\left(300{ }^{\circ} \mathrm{C}\right)$ by increasing the carbon content.

\section{Diffusionless Growth of Ferrite}

This is not the proper occasion for discussing all pros and cons for the diffusional and diffusionless growth 

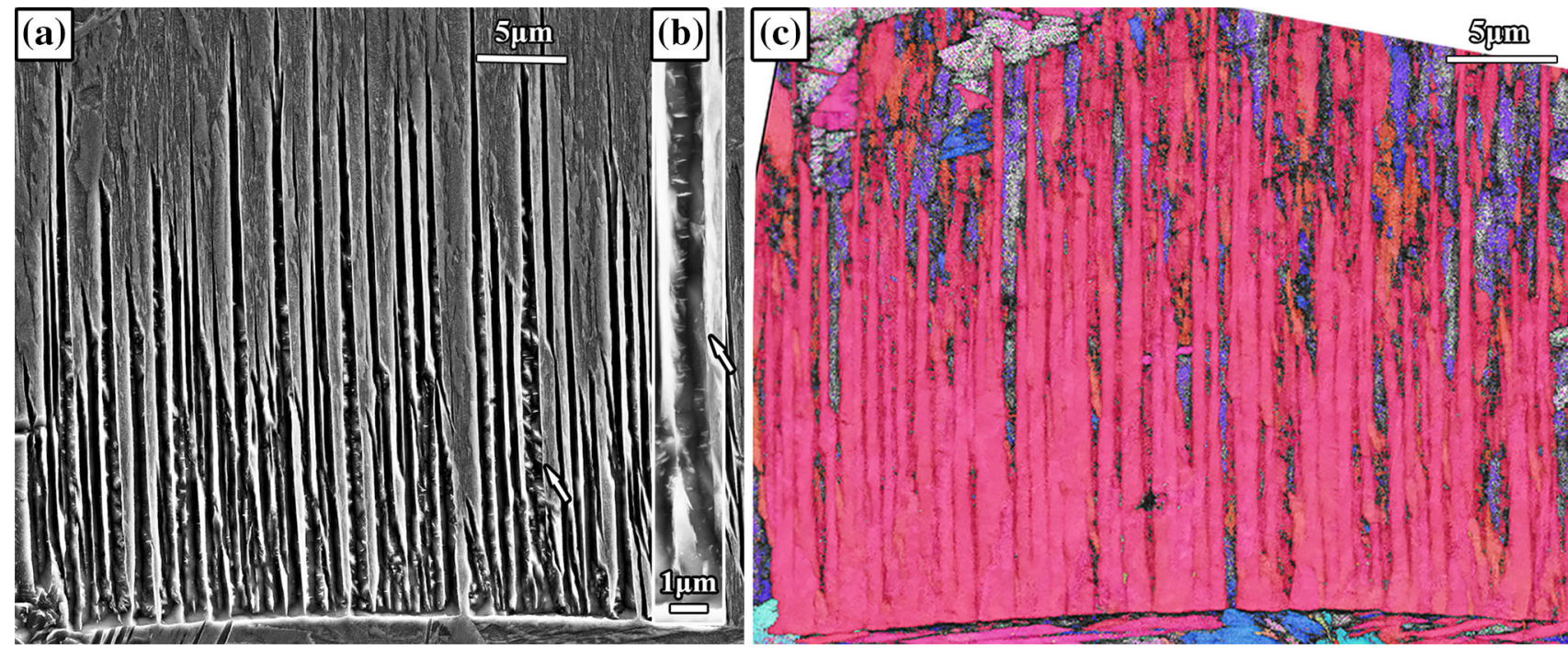

Fig. 27- $(a, b)$ SEM and $(c)$ EBSD orientation map (inverse pole figure in z direction overplayed with pattern quality map, 83.7 pct indexing success rate and 0 pct cleanup); after $1.5 \mathrm{~s}$ at $723 \mathrm{~K}\left(450{ }^{\circ} \mathrm{C}\right)$. Note the insert $(\mathrm{b})$, which reveals the true size of the cementite particles, is from longer time of etching compared to (a). The arrows indicate the same plate shown in different magnification. For color version of this figure, the reader is referred to the online version.

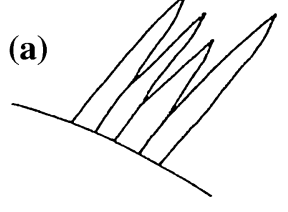

(b)

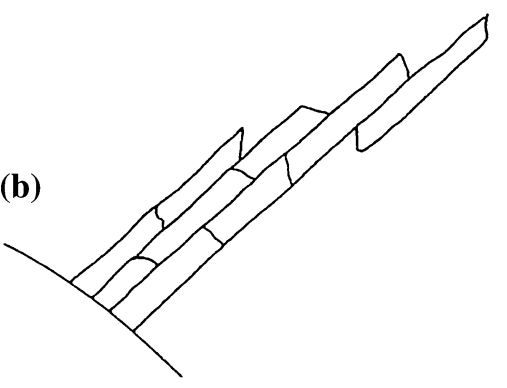

(c)

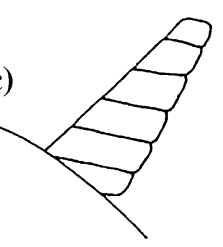

Fig. 28 - Sketches of $(a)$ Widmanstätten ferrite, $(b)$ upper bainite, and $(c)$ lower bainite. From Oblak and Hehemann. ${ }^{[25]}$

models of bainite formation. The discussion will only concern the observations made in the present work. It has already been demonstrated that they can be interpreted in terms of the diffusional growth model. The applicability of the diffusionless growth model will now be discussed.

According to the diffusionless model, the growth of primary plates of ferrite in upper bainite is predicted to be rapid enough to prevent carbon diffusion. However, it is necessary that diffusion is involved in the stage where cementite forms. That stage is rarely discussed in any detail. As an exception, Sandvik ${ }^{[22]}$ published a separate paper on the second stage that is initiated by carbide precipitation. However, he used high silicon contents and the second stage took 24 hours at $653 \mathrm{~K}$ $\left(380{ }^{\circ} \mathrm{C}\right)$ to be compared to a few seconds in the present alloys. The carbide was not cementite, due to the high silicon content and also chromium or manganese.
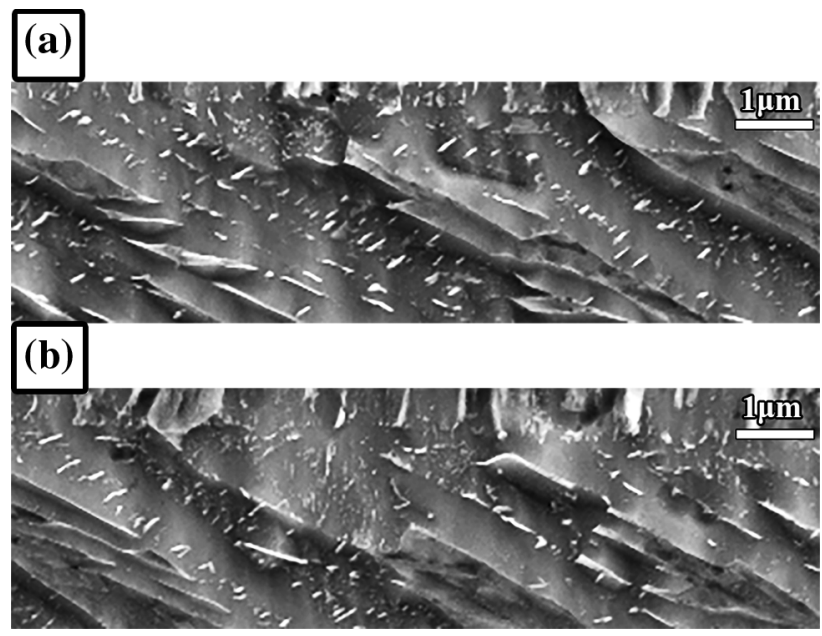

Fig. 29-SEM of FeSiC alloy after $1 \mathrm{~s}$ at $673 \mathrm{~K}\left(400{ }^{\circ} \mathrm{C}\right)$, showing mixtures of two kinds of bainitic microstructures, $(a)$ and $(b)$ are from the same feather.

A widely published sketch of various stages in the formation of upper bainite according to the diffusionless hypothesis is reproduced in Figure $30 .{ }^{[2]}$ For ferrite it only shows the formation of a series of subunits, which is assumed to be diffusionless. It does not illustrate how additional ferrite forms in the final stage when cementite initiates the decomposition of the remaining austenite in the interspaces. To take Figures 14 and 20 as examples, there can hardly be any disagreement that the carbide-free bands of ferrite in the middle of the units represent the primary plates of ferrite and the two layers of ferrite with fine cementite particles were formed by decomposition of austenite. In the lower part of Figure 20 it is even evident that this decomposition is still progressing on both sides, in Figure 14 on both sides. It should be possible to agree that the final stage of 


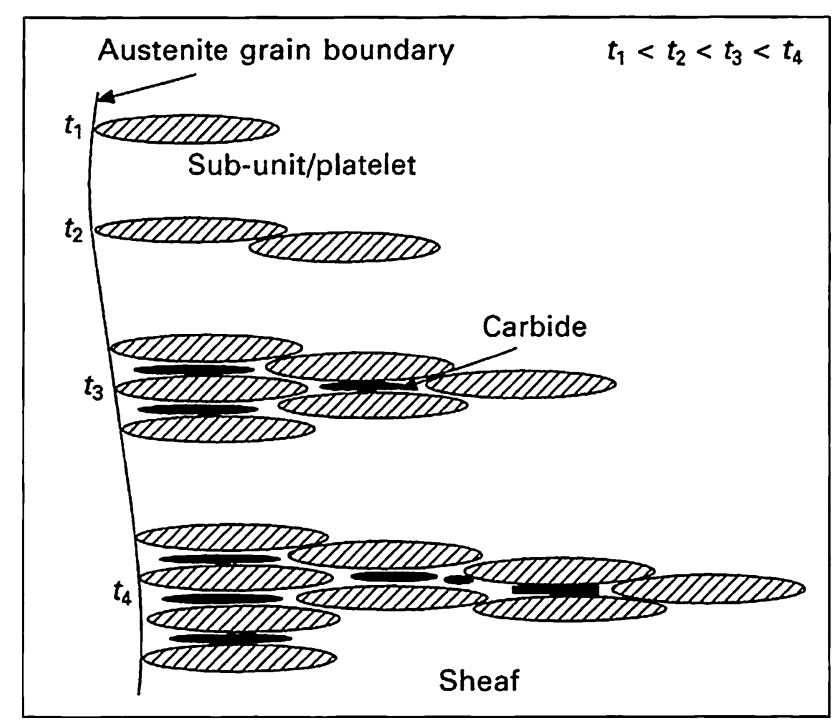

Fig. 30-Schematic illustration of microstructural features of upper bainite. Adapted by Singh. ${ }^{[2]}$ Originally from Bhadeshia and Honeycombe. ${ }^{[30]}$

upper bainite formation is a eutectoid transformation to cementite and ferrite. The only disagreement would be whether carbon is ejected from the ferrite plates during their growth or soon after they have stopped growing.

Another question concerns Figure 4 where six fine plates of ferrite have merged. It does not seem reasonable that rapid diffusionless growth could have brought all six plates into close contact with each other which is required for the merger. It seems necessary that the close contact was established by some diffusional thickening. The diffusionless hypothesis should be modified by adding diffusional thickening of the primary plates. That is also supported by the observation of rumpling by Ohmori et al. ${ }^{[18]}$ as discussed above.

To retain the diffusionless growth model for upper bainite it thus seems necessary to abandon the proposed role of subunits in the lengthening of ferrite plates and to accept (1) continuous lengthening, (2) thickening by a diffusional growth process, and (3) formation of cementite by a eutectoid transformation. However, then there will be no role left for a diffusionless process. On the other hand, the displacive growth process could still apply.

The situation is completely different for lower bainite where the diffusionless hypothesis predicts that the fine two-phase mixtures are the result of precipitation of cementite inside supersaturated ferrite.

\section{SUMMARY AND CONCLUSIONS}

The development of upper bainite has been examined metallographically on low alloyed steels with 0.3 mass pct $\mathrm{C}$. The second stage which involves cementite formation, was studied in detail and it was concluded that it may occur as a eutectoid transformation with considerable cooperation. Typical upper bainite forms with a degenerate eutectoid reaction but many results of a cooperative eutectoid reaction were found, particularly in the lower temperature range.

When the cooperative eutectoid reaction occurs in interspaces, it does not affect the overall predominance of ferrite plates. It is proposed that typical lower bainite will form when the cooperative eutectoid reaction predominates. The present study of bainite was extended below the $M_{\mathrm{S}}$ temperature in the hope of finding signs of increased importance of the cooperative reaction at lower temperatures. Such signs were not found in the present alloys with 0.3 mass pet $C$.

It is suggested that the study of effects of various factors on the bainitic microstructure should be focused on their effects on three basic factors, the tendency to form ferrite plates, the tendency to form cementite in the presence of austenite and ferrite, and the tendency for the eutectoid reaction to turn cooperative.

The observations made in the present study could be interpreted in terms of the diffusional growth model of bainite. A number of modifications are required for the diffusionless mode.

\section{ACKNOWLEDGMENTS}

This work has been performed within the VINN Excellence Centre Hero-m, financed by VINNOVA, the Swedish Governmental Agency for Innovation Systems, Swedish industry and KTH Royal Institute of Technology. J. Yin would like to thank China Scholarship Council (CSC) for sponsorship of his study.

\section{OPEN ACCESS}

This article is distributed under the terms of the Creative Commons Attribution 4.0 International License (http://creativecommons.org/licenses/by/4.0/), which permits unrestricted use, distribution, and reproduction in any medium, provided you give appropriate credit to the original author(s) and the source, provide a link to the Creative Commons license, and indicate if changes were made.

\section{REFERENCES}

1. J. Yin, M. Hillert, and A. Borgenstam: Metall. Mater. Trans. A, in press, DOI:10.1007/s11661-016-3903-y.

2. S.B. Singh: in Phase Transformation in Steels, E. Pereloma and D.V. Edmonds, eds., Woodhead Publishing, Oxford, 2012, pp. 385-416.

3. T. Furuhara: in Phase Transformation in Steels, E. Pereloma and D.V. Edmonds, eds., Woodhead Publishing, Oxford, 2012, pp. 417-35.

4. R.F. Mehl: Hardenability of Alloy Steels, ASM, Metals Park, OH, 1939, pp. 41-44.

5. C. Zener: Trans. AIME, 1946, vol. 167, pp. 550-83.

6. T. Ko and S.A. Cottrell: J. Iron Steel Inst., 1952, vol. 172, pp. 307-13.

7. M. Hillert: Jernkont. Ann., 1957, vol. 141, pp. 757-89.

8. R.F. Hehemann, K.R. Kinsman, and H.I. Aaronson: Metall. Trans., 1972, vol. 3, pp. 1077-94. 
9. S.J. Matas and R.F. Hehemann: Trans. AIME, 1961, vol. 221, pp. 179-85.

10. K.W. Andrews: I. Iron Steel Inst., 1965, vol. 203, pp. 721-26.

11. A. Stormvinter, A. Borgenstam, and J. Agren: Metall. Mat. Trans. A, 2012, vol. 43A, pp. 3870-79.

12. H. Modin and S. Modin: Metallurgical Microscopy, Butterworths, London, 1973, p. 375.

13. H. Ohtani, S. Okaguchi, Y. Fujishiro, and Y. Ohmori: Metall. Trans. A, 1990, vol. 21A, pp. 877-88.

14. A. Hultgren: Trans. ASM, 1947, vol. 39, pp. 915-89.

15. M. Hillert: The Decomposition of Austenite by Diffusional Processes, V.F. Zackay and H.I Aaronson, eds., Interscience, New York, 1962, pp. 197-237.

16. S.B. Singh and H.K.D.H. Bhadeshia: Mater. Sci. Eng. A, 1998, vol. A245, pp. 72-79.

17. S. Modin and H. Modin: Jernkont. Ann., 1955, vol. 139, pp. 481-515.

18. Y. Ohmori: ISIJ Int., 2001, vol. 41, pp. 554-65.

19. T. Ko: J. Iron Steel Inst., 1953, vol. 175, pp. 16-18.

20. A.P. Miodownik: The Mechanisms of Phase Transformations in Metals, Institute of Metals, London, 1956, pp. 319-21.
21. R. Le Houillier, G. Bégin, and A. Dubé: Metall. Trans., 1971, vol. 2, pp. 2645-53.

22. S.P.J. Sandvik: Metall. Trans. A, 1982, vol. 13A, pp. 789-800.

23. K. Tsuzaki, A. Kodai, and T. Maki: Metall. Mater. Trans. A, 1994, vol. 25A, pp. 2009-16.

24. H.I. Aaronson and C. Wells: Trans. AIME, 1956, vol. 206, pp. 1216-23.

25. J.M. Oblak and R.F. Hehemann: Transformations and Hardenability in Steels, Climax Molybdenum Co., Ann Arbor, MI, 1967, pp. 15-38.

26. Y. Ohmori, H. Ohtani, and T. Kunitake: Trans. ISIJ, 1971, vol. 11 , pp. $250-59$.

27. H.K.D.H. Bhadeshia: Acta Metall., 1980, vol. 28, pp. 1103-14.

28. F.B. Pickering: Transformations and Hardenability in Steels, Climax Molybdenum Co., Ann Arbor, MI, 1967, pp. 109-29.

29. Y. Ohmori and R.W.K. Honeycombe: Suppl. Trans. ISIJ, 1971, vol. 11, pp. 1160-64.

30. H.K.D.H. Bhadeshia and R.W.K. Honeycombe: Steels: Microstructure and Properties, 3rd ed., Butterworth-Heinemann, Oxford, 2006, p. 139. 